University of Tennessee Health Science Center UTHSC Digital Commons

\title{
8-2017
}

\section{Metabolic Regulation of Cellular Signaling}

\author{
Rashid John Darbandi \\ University of Tennessee Health Science Center
}

Follow this and additional works at: https://dc.uthsc.edu/dissertations

Part of the Medical Biochemistry Commons, Medical Cell Biology Commons, and the Neoplasms Commons

\section{Recommended Citation}

Darbandi, Rashid John (http://orcid.org/0000-0002-1239-6191), "Metabolic Regulation of Cellular Signaling" (2017). Theses and Dissertations (ETD). Paper 440. http://dx.doi.org/10.21007/ etd.cghs.2017.0562.

This Dissertation is brought to you for free and open access by the College of Graduate Health Sciences at UTHSC Digital Commons. It has been accepted for inclusion in Theses and Dissertations (ETD) by an authorized administrator of UTHSC Digital Commons. For more information, please contact jwelch30@uthsc.edu. 


\title{
Metabolic Regulation of Cellular Signaling
}

\author{
Abstract \\ Using the biochemically tractable Xenopus oocyte model system, we have previously characterized a \\ novel metabolic regulation of cell death. We found that glucose-6-phosphate (G6P) via the pentose \\ phosphate pathway leads to increased nicotinamide adenine dinucleotide phosphate (NADPH) levels, a \\ subsequent increase in cytosolic acetyl-coenzyme $A$ and activation of $\mathrm{Ca} 2+$ /calmodulin-dependent \\ protein kinase II (CaMKII). We recently identified coenzyme A (CoA), derived from the breakdown of \\ acetyl-CoA, as the key metabolic signal that mediates a novel mechanism of calmodulindependent \\ activation of CaMKII. CoA binds directly to the calmodulin (CaM) binding domain (CaMBD) of CaMKII \\ resulting in its activation and downstream inhibitory phosphorylation of caspase-2, suppressing \\ apoptosis. In this dissertation, we questioned whether there are other CaMBD containing proteins \\ metabolically regulated by CoA. In an unbiased approach, CaM binding proteins were first isolated from \\ Xenopus extract using a CaM-Sepharose column. Purified CaM binding proteins were then incubated with \\ CoA-Sepharose in a second purification step and resolved by sodium dodecyl sulfate polyacrylamide gel \\ electrophoresis (SDS-PAGE) and silver staining. The results indicate the presence of numerous CaM- \\ binding proteins that also bind $\mathrm{CoA}$ and are thus potentially metabolically regulated. In a targeted \\ approach, we tested the ability of aberrant glucose signaling to regulate the CaM-binding protein $\mathrm{PI} 3 \mathrm{~K}$. We \\ found that addition of G6P, mimicking aberrant glucose metabolism, or CoA to X. laevis egg extracts \\ activated Akt in a phosphatidylinositol 3-kinase (PI3K), phosphoinositidedependent protein kinase \\ 1(PDPK1)-dependent manner. Additionally, we show that CoA binds directly to and activates PI3K. These \\ findings uncover a novel mechanism of PI3K activation by aberrant glucose metabolism and suggest a \\ potentially unknown constitutive activation pathway of PI3K/Akt by aberrant glucose signaling. \\ Document Type \\ Dissertation \\ Degree Name \\ Doctor of Philosophy (PhD) \\ Program \\ Biomedical Sciences \\ Research Advisor \\ Leta K. Nutt \\ Keywords \\ Akt, Cancer, Metabolism, PI3K, Signaling, Warburg \\ Subject Categories \\ Diseases | Medical Biochemistry | Medical Cell Biology | Medical Sciences | Medicine and Health Sciences \\ | Neoplasms
}


Metabolic Regulation of Cellular Signaling

\author{
A Dissertation \\ Presented for \\ The Graduate Studies Council \\ The University of Tennessee \\ Health Science Center
}

\author{
In Partial Fulfillment \\ Of the Requirements for the Degree \\ Doctor of Philosophy \\ From The University of Tennessee
}

By

Rashid John Darbandi

August 2017 
Copyright (C) 2017 by Rashid John Darbandi.

All rights reserved. 


\section{DEDICATION}

This dissertation is dedicated to my parents, Javad and Alice Darbandi, for their encouragement, love and support. Also, to Dr. Leta Nutt for her mentorship and friendship over so many years. 


\section{ACKNOWLEDGEMENTS}

I would like to first and foremost acknowledge Dr. Nutt for taking me under her wing at Duke University, supporting me over so many years, and for allowing me the opportunity to work in her lab. Also, to her husband, Jan Bouten, for his advice and friendship since the first day I arrived in Memphis. I'd like to also thank former lab members Dr. Francis McCoy and Si-Ing Chen for their friendship, discussions, and general guidance.

I thank the faculty members of my committee, Drs. Gerard Zambetti, Paul Mead, Xinwei Cao, Suzanne Baker, and Zhaohui $\mathrm{Wu}$, for their guidance as I pursued my doctoral degree. I'd like to further thank Dr. Zambetti for opening the door and allowing me the opportunity to come work at St. Jude prior to my matriculation as well as his encouragement and professional support over the years thereafter. Also, Drs. Mead and Cao for their personal friendship and invaluable feedback. I sincerely appreciate the time all my committee members invested in my education and the opportunity to learn from such distinguished scientists.

I'd also like to thank the Alma and Hal Reagan Endowment Fund as well as the American Cancer Society for funding. 


\begin{abstract}
Using the biochemically tractable Xenopus oocyte model system, we have previously characterized a novel metabolic regulation of cell death. We found that glucose-6-phosphate (G6P) via the pentose phosphate pathway leads to increased nicotinamide adenine dinucleotide phosphate (NADPH) levels, a subsequent increase in cytosolic acetyl-coenzyme $\mathrm{A}$ and activation of $\mathrm{Ca}^{2+} /$ calmodulin-dependent protein kinase II (CaMKII). We recently identified coenzyme A (CoA), derived from the breakdown of acetyl-CoA, as the key metabolic signal that mediates a novel mechanism of calmodulindependent activation of CaMKII. CoA binds directly to the calmodulin (CaM) binding domain (CaMBD) of CaMKII resulting in its activation and downstream inhibitory phosphorylation of caspase-2, suppressing apoptosis. In this dissertation, we questioned whether there are other CaMBD containing proteins metabolically regulated by CoA. In an unbiased approach, CaM binding proteins were first isolated from Xenopus extract using a CaM-Sepharose column. Purified CaM binding proteins were then incubated with CoA-Sepharose in a second purification step and resolved by sodium dodecyl sulfate polyacrylamide gel electrophoresis (SDS-PAGE) and silver staining. The results indicate the presence of numerous CaM-binding proteins that also bind CoA and are thus potentially metabolically regulated. In a targeted approach, we tested the ability of aberrant glucose signaling to regulate the CaM-binding protein PI3K. We found that addition of G6P, mimicking aberrant glucose metabolism, or CoA to $X$. laevis egg extracts activated Akt in a phosphatidylinositol 3-kinase (PI3K), phosphoinositidedependent protein kinase 1(PDPK1)-dependent manner. Additionally, we show that CoA binds directly to and activates PI3K. These findings uncover a novel mechanism of PI3K activation by aberrant glucose metabolism and suggest a potentially unknown constitutive activation pathway of PI3K/Akt by aberrant glucose signaling.
\end{abstract}




\section{TABLE OF CONTENTS}

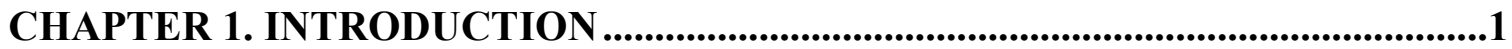

Altered Metabolism Is a Hallmark of Cancer ............................................................. 1

The Warburg Effect ......................................................................................... 1

The PI3K/Akt/mTORC1 Pathway ...........................................................................

The Pentose Phosphate Pathway and Cancer .............................................................6

Metabolic Regulation of Programmed Cell Death ...................................................

CHAPTER 2. MATERIALS AND METHODS.......................................................11

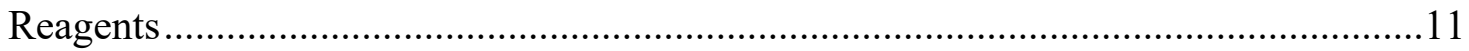

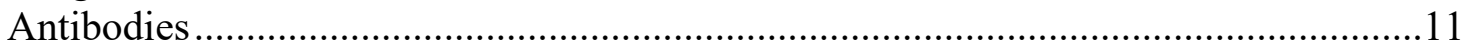

Preparation of Xenopus Extract and Extract Cytosol ............................................. 12

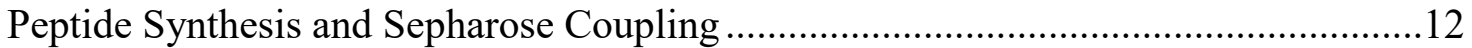

CoA/CaM Tandem Purification................................................................................ 12

PI3K TLC Assays and Spot Quantification ................................................................ 14

Depletions of Egg Extract and Coupled-Sepharose Binding Assays ..........................14

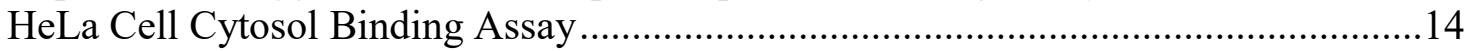

CHAPTER 3. IDENTIFICATION OF NOVEL COA/CAM INTERACTORS ........16

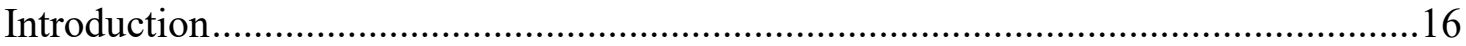

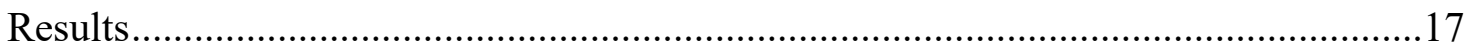

CaM-binding proteins are efficiently purified from Xenopus extract ......................17

Numerous CaM-binding proteins exist that also bind CoA ................................... 17

\section{CHAPTER 4. METABOLIC ACTIVATION OF PHOSPHATIDYLINOSITOL}

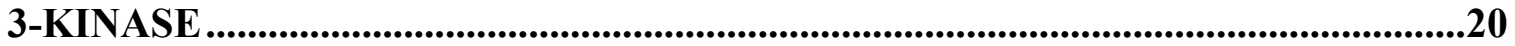

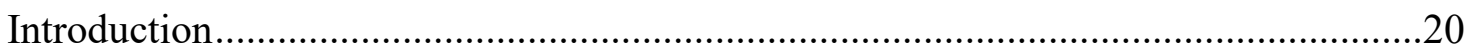

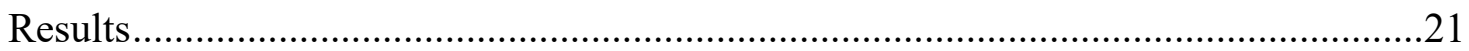

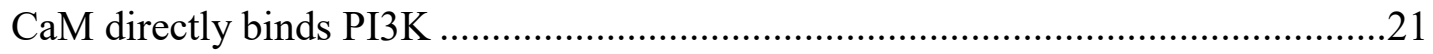

pIRS (Y608) induces Akt phosphorylation in Xenopus extract ..............................21

Aberrant glucose signaling activates Akt ........................................................24

Aberrant glucose metabolic activation of Akt is PI3K- and PDPK1-dependent .......24

CoA mediates a novel metabolic activation of PI3K/Akt ...................................27

CoA activation of Akt is PI3K-dependent ..........................................................29

Coenzyme A directly binds and activates class I PI3K .....................................29

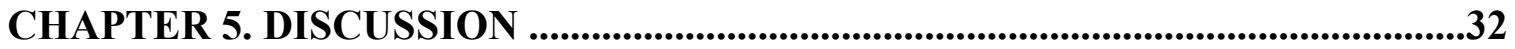

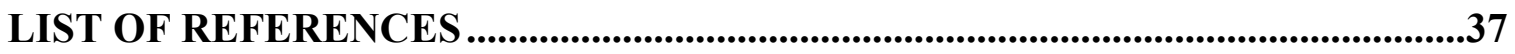

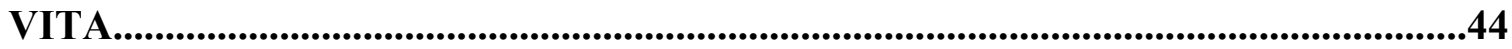




\section{LIST OF FIGURES}

Figure 1-1 Canonical activation of class IA PI3K by RTKs. .....................................4

Figure 1-2. Glycolysis and the pentose phosphate pathway are tightly linked glucose catabolic pathways. ...........................................................................

Figure 1-3. A model of the noncanonical activation of CaMKII by altered glucose signaling.

Figure 2-1. Tandem purification of $\mathrm{CaM} / \mathrm{CoA}$ binding proteins from Xenopus egg

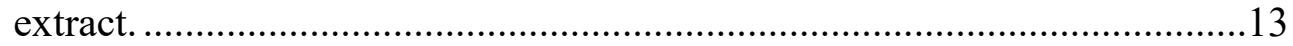

Figure 3-1. Purification of $\mathrm{CaM} / \mathrm{CoA}$ interactors from Xenopus extract......................18

Figure 4-1. Calmodulin directly binds PI3K. .......................................................22

Figure 4-2. Aberrant glucose signaling activates Akt. ..............................................23

Figure 4-3. Aberrant glucose metabolic activation of Akt is PI3K and PDPK1dependent. .25

Figure 4-4. CoA mediates a novel metabolic activation of PI3K/Akt.........................28

Figure 4-5. Coenzyme A directly binds and activates class I PI3K. ............................30

Figure 5-1. CoA binds endogenous CaMKIV and Calcineurin...................................33

Figure 5-2. CoA directly binds and activates PI3K, mediating the novel metabolic activation of PI3K/Akt. 


\section{LIST OF ABBREVIATIONS}

$\begin{array}{ll}\text { AIF } & \text { Apoptosis-inducing factor } \\ \text { ATP } & \text { Adenosine triphosphate } \\ \text { BAD } & \text { Bcl-2-associated death promotor } \\ \text { C } & \text { Chicken } \\ \text { CaM } & \text { Calmodulin } \\ \text { CaMBD } & \text { Calmodulin binding domain } \\ \text { CaMKII } & \text { Calcium/calmodulin-dependent protein kinase II } \\ \text { CaMKIV } & \text { Calcium/calmodulin-dependent protein kinase IV } \\ \text { CoA } & \text { Coenzyme A } \\ \text { DNA } & \text { Deoxyribonucleic acid } \\ \text { EGFR } & \text { Epidermal growth factor receptor } \\ \text { EDTA } & \text { Ethylenediaminetetraacetic acid } \\ \text { EGTA } & \text { ethylene glycol-bis( }(\text {-aminoethyl ether)-N,N,N',N'-tetraacetic acid } \\ \text { F6P } & \text { Fructose-6-phosphate } \\ \text { FGFR } & \text { Fibroblast growth factor receptor } \\ \text { Fox } & \text { Forkhead box } \\ \text { G3P } & \text { Glyceraldehyde 3-phosphate } \\ \text { G6P } & \text { Glucose-6-phosphate } \\ \text { G6PD } & \text { Glucose-6-phosphate dehydrogenase } \\ \text { GAPDH } & \text { Glyceraldehyde 3-phosphate dehydrogenase } \\ \text { GPCR } & \text { G-protein coupled receptor } \\ \text { GSK } & \text { GSK2334470 } \\ \text { GSK3 } \beta & \text { Glycogen synthase kinase 3 beta } \\ \text { GTP } & \text { Guanosine triphosphate } \\ \text { HEPES } & \text { 4-(2-hydroxyethyl)-1-piperazineethanesulfonic acid } \\ \text { HER } & \text { Human epidermal growth factor receptor } \\ \text { HIF1 } & \text { Hypoxia inducible factor 1 } \\ \text { HK } & \text { Hexokinase } \\ \text { InsR } & \text { Insulin receptor } \\ \text { IRS1 } & \text { Insulin receptor substrate 1 } \\ \text { kDa } & \text { Kilodalton } \\ \text { LDHA } & \text { Lactate dehydrogenase } \\ \text { LY } & \text { LY294002 } \\ \text { Mdm2 } & \text { Mouse double minute 2 homolog } \\ \text { MgAc } & \text { Magnesium acetate } \\ \text { MgCl } & \text { Magnesium chloride } \\ \text { mTORC } & \text { Mammalian target of rapamycin complex } \\ \text { NAD } & \text { Nicotinamide adenine dinucleotide } \\ \text { NADPH } & \text { Nicotinamide adenine dinucleotide phosphate } \\ \text { PDGFR } & \text { Platelet derived growth factor receptor } \\ \text { PDH } & \text { Pyruvate dehydrogenase } \\ \text { PDK1 } & \text { Pyruvate dehydrogenase kinase 1 } \\ \text { PDPK1 } & \end{array}$




$\begin{array}{ll}\text { PET } & \text { Positron Emission Tomography } \\ \text { PFK1 } & \text { Phosphofructokinase-1 } \\ \text { PFK2 } & \text { Phosphofructokinase-2 } \\ \text { PI3K } & \text { Phosphatidylinositol 3-kinase } \\ \text { PIP2 } & \text { Phosphatidylinositol-4,5-bisphosphate } \\ \text { PIP2-8 } & \text { D-myo-phosphatidylinositol-4,5-bisphosphate diC8 } \\ \text { PIP2-16 } & \text { D-myo-phosphatidylinositol-4,5-bisphosphate diC16 } \\ \text { PIP3 } & \text { Phosphatidylinositol-3,4,5-triphosphate } \\ \text { PIP3-16 } & \text { D-myo-phosphatidylinositol-3,4,5-trisphosphate diC16 } \\ \text { PK } & \text { Pyruvate kinase } \\ \text { PKM } & \text { Pyruvate kinase muscle isozyme } \\ \text { PPP } & \text { Pentose phosphate pathway } \\ \text { PTEN } & \text { Phosphatase and tensin homolog } \\ \text { R5P } & \text { Ribose-5-phosphate } \\ \text { Rheb } & \text { Ras homolog enriched in brain } \\ \text { RNA } & \text { Ribonucleic acid } \\ \text { ROS } & \text { Reactive oxygen species } \\ \text { RTK } & \text { Receptor tyrosine kinase } \\ \text { SCO2 } & \text { Synthesis of cytochrome c oxidase 2 } \\ \text { SDS-PAGE } & \text { Sodium dodecyl sulfate polyacrylamide gel electrophoresis } \\ \text { SREBP } & \text { Sterol regulatory element-binding protein } \\ \text { SmMLCK } & \text { Smooth muscle myosin light chain kinase } \\ \text { TCA } & \text { Tricarboxylic acid } \\ \text { TIGAR } & \text { TP53-induced glycolysis and apoptosis regulator } \\ \text { TKT } & \text { Transketolase } \\ \text { TLC } & \text { Thin layer chromatography } \\ \text { TPI1 } & \text { Triosephosphate isomerase-1 } \\ \text { Tris-Hcl } & \text { tris(hydroxymethyl)aminomethane-hydrochloric acid } \\ \text { VHL } & \text { von Hippel-Lindau } \\ \text { X } & \text { Xenopus } \\ \text { 2D-G6P } & \text { 2-deoxyglucose-6-phosphate } \\ & \end{array}$




\section{CHAPTER 1. INTRODUCTION}

\section{Altered Metabolism Is a Hallmark of Cancer}

Cancer is a disease of uncontrolled cellular growth with the potential to metastasize to other tissues and organs (1). Understanding the cellular signaling pathways that become dysregulated and underlie the transformation of a normal cell to a cancer cell with limitless proliferative capacity is pivotal to develop effective treatments. Although cancer is a highly heterogenous disease, the physiological effects of such altered signaling pathways summarize the core hallmarks of cancer cells: anti-growth signals, self-sufficiency in growth signals, evasion of apoptosis, limitless replicative potential, sustained angiogenesis, metastasis, immune system evasion, unstable DNA, inflammation and dysregulated metabolism $(2,3)$. Our focus here is on the altered metabolism of tumor cells and its regulation of major signaling pathways.

Cellular metabolism is significantly rewired in cancer cells to support their rapid proliferation and continuous growth. In a normal cell, nutrient uptake and metabolism is tightly regulated, preventing abnormal proliferation (4). Cancer cells circumvent these metabolic control systems through the acquisition of genetic mutations in key tumor suppressors and oncogenes (5). Such metabolic reprogramming, while heterogenous across tumor cells, serves a common purpose in providing: sufficient energy (ATP and NADPH), building blocks to synthesize macromolecules, and reducing agents to counter high production of reactive oxygen species (ROS) (6). Some of the major metabolic alterations found in tumor cells that support the bioenergetic demands of their excessive growth include increased glycolysis, elevated amino acid and lipid metabolism, increased glutaminolysis, enhanced mitochondrial biogenesis, and induction of the pentose phosphate pathway (7). Here, we focus on the coordinated increase in glycolysis and the pentose phosphate pathway that supports the limitless proliferative capacity of tumor cells.

\section{The Warburg Effect}

First characterized by Dr. Otto Warburg and hence referred to as the "Warburg effect," cancer cells preferentially catabolize glucose via glycolysis even in the presence of oxygen (8-10). In a normal cell, glucose is completely oxidized via glycolysis, the tricarboxylic acid (TCA) cycle, and mitochondrial oxidative phosphorylation to produce an optimal yield of 36 ATP molecules for each molecule of glucose. While normal cells prioritize glycolysis only under anaerobic conditions (7), cancer cells preferentially metabolize glucose to pyruvate via glycolysis followed by its conversion to lactate. This circumvention of the TCA cycle and mitochondrial oxidative phosphorylation yields only 2 molecules of ATP per each molecule of glucose. However, tumor cells compensate for this by increasing glucose uptake and elevating the expression as well as the activity of glycolytic enzymes. 
One of the major features distinguishing tumor cells from normal cells is their increased uptake of glucose mediated by an upregulation of glucose transporters (11-14). Indeed, this difference allows for the visualization of tumors by Positron Emission Tomography (PET) using radiolabeled glucose analogs such as ${ }^{18} \mathrm{~F}$-fluorodeoxyglucose as tracers (7). With a greater amount of substrate available for glycolysis, tumor cells concomitantly increase the expression and activity of glycolytic enzymes, together supporting an enhanced glycolytic flux.

The elevated expression and activity of glycolytic enzymes in cancer cells is mediated by enhanced transcriptional activity of hypoxia inducible factor-1 (HIF1) and Myc as well as loss of p53-mediated control (7). HIF1 is elevated in many cancers through gain of function mutations in major oncogenes such as phosphatidylinositol 3kinase/Akt, Ras, and human epidermal growth factor receptor (HER) as well as through the loss of key tumor suppressors p53, von Hippel-Lindau (pVHL), and phosphatase and tensin homolog (PTEN), the negative regulator of the PI3K/Akt axis (15). The oncogene MYC encodes a transcription factor responsible for regulating a vast number of human genes involved in cell cycle, metabolism, ribosome biogenesis, apoptosis and transformation (15). In terms of the Warburg effect, Myc and HIF1 promote the expression of glucose transporters as well as key glycolytic enzymes including hexokinase 2 (HK2), phosphofructokinase-1 (PFK1), triosephosphate isomerase-1 (TPI1) and lactate dehydrogenase A (LDHA), among others (4, 11, 16-20). Myc also mediates the enhanced glutaminolysis observed in many cancer cells (21).

In contrast, the tumor suppressor $\mathrm{p} 53$ downregulates HK2 expression while enhancing expression of TP53-induced glycolysis and apoptosis regulator (TIGAR), synthesis of cytochrome c oxidase 2 (SCO2) and apoptosis-inducing factor (AIF) (22). TIGAR via dephosphorylation, reduces the levels of fructose-2, 6-bisphosphate, an important allosteric activator of the key glycolytic enzyme PFK1 (23). SCO2 regulates the cytochrome c oxidase complex, promoting mitochondrial respiration (5) while AIF is vital for the function of complex I in the electron transport chain (24). p53 also suppresses glucose uptake by directly inhibiting the transcription of glucose transporters Glut1 and Glut4 $(25,26)$ and suppressing the expression of Glut3 $(26)$. The net effects of wild-type p53 are therefore to decrease glycolytic flux and promote mitochondrial oxidative phosphorylation $(22,27)$. In addition, p53 is a negative regulator of HIF1 (28) while HIF1 is an enhancer of Myc transcription (18). Together, p53, Myc and HIF1 constitute an interconnected triad of master transcription factors responsible for the altered glycolytic phenotype observed in tumor cells $(16,18,29)$.

While normal cells, under aerobic conditions, convert the glycolytic end-product pyruvate to acetyl-CoA to fuel the TCA cycle, tumor cells preferentially convert pyruvate to lactate even in the presence of oxygen due to an upregulation of LDHA, mediated by Myc and HIF1 (18). In addition, Myc and HIF1 also induce expression of pyruvate dehydrogenase kinase 1 (PDK1) (18), a negative regulator of pyruvate dehydrogenase (PDH), the first component enzyme of the pyruvate dehydrogenase complex, responsible for the conversion of pyruvate to acetyl-CoA. The net result is an increased production of lactate and a circumvention of the TCA cycle and mitochondrial oxidative 
phosphorylation. The preferential conversion of pyruvate to lactate, mediated by LDHA overexpression, allows tumor cells to rapidly regenerate the nicotinamide adenine dinucleotide $\left(\mathrm{NAD}^{+}\right)$consumed by glycolysis and thus supports an accelerated glycolytic rate $(11,16,17,19,30)$. Indeed, LDHA is upregulated in a diverse array of human cancers including pancreatic cancer (31), hepatocellular carcinoma (32), breast cancer (33), esophageal squamous cell carcinoma (34) and prostate cancer (35), and its overexpression has been linked to tumor initiation, growth and maintenance (36). Furthermore, the excretion of lactate lowers the extracellular $\mathrm{pH}$ which enhances the activity of metalloproteases to break down extracellular matrix and ultimately facilitate cancer invasion and metastasis $(37,38)$.

Thus, despite producing significantly less ATP per each molecule of glucose, tumor cells compensate by increasing glucose uptake, rapidly regenerating $\mathrm{NAD}^{+}$, and ultimately enhancing glycolytic flux. Importantly, this provides tumor cells not only with energy in the form of ATP, but also key glycolytic intermediates which are necessary precursors for biosynthesis (7). For instance, G6P can enter the pentose phosphate pathway to generate ribose-5-phosphate (R5P), an important precursor to many biomolecules including nucleotides (5), as well as NADPH which is required for reductive anabolic biosynthesis and redox balance. Dihydroxacetone phosphate generated in glycolysis can be used to synthesize lipids required for cell growth and division (7). Additionally, the amino acids serine, cysteine and glycine are generated from the glycolytic intermediate 3-phosphoglycerate (39). In this manner, the metabolic rewiring observed in tumor cells provides a significant proliferative advantage by allowing for the accumulation of important glycolytic intermediates necessary for cell growth, DNA replication, and cell division.

\section{The PI3K/Akt/mTORC1 Pathway}

The PI3K pathway is a vital signal transduction system that links multiple receptor classes to a diverse array of essential cellular functions including metabolism, inflammation, cell survival, growth, motility and apoptosis (40). While three distinct classes of PI3K exist, the class IA PI3Ks have been implicated in cancer (41) and will be the focus here. Class IA PI3Ks are heterodimers comprised of a catalytic p110 subunit and a regulatory p85 subunit. The three members of this class, $\mathrm{p} 110 \alpha / \mathrm{p} 85, \mathrm{p} 110 \beta / \mathrm{p} 85$ and $\mathrm{p} 110 \delta / \mathrm{p} 85$, are activated downstream of receptor tyrosine kinases (RTKs) (Figure 1-1) as well as G-protein coupled receptors (GPCRs) in the case of p110 $\beta / \mathrm{p} 85$ and p1108/p85. Focusing on the former, upon growth factor binding and subsequent activation of RTKs, PI3K is recruited to the membrane via binding of the p85 regulatory subunit directly to phosphorylated tyrosine residues on the cytoplasmic domain of the activated RTK (e.g. platelet derived growth factor receptor [PDGFR]) or on an adaptor protein recruited to and phosphorylated by the RTK (e.g. epidermal growth factor receptor [EGFR], HER2, insulin receptor [InsR], fibroblast growth factor receptor [FGFR]) (41). This binding not only recruits PI3K to its lipid substrate, phosphatidylinositol-4,5-bisphosphate (PIP2), at the plasma membrane, it also relieves 


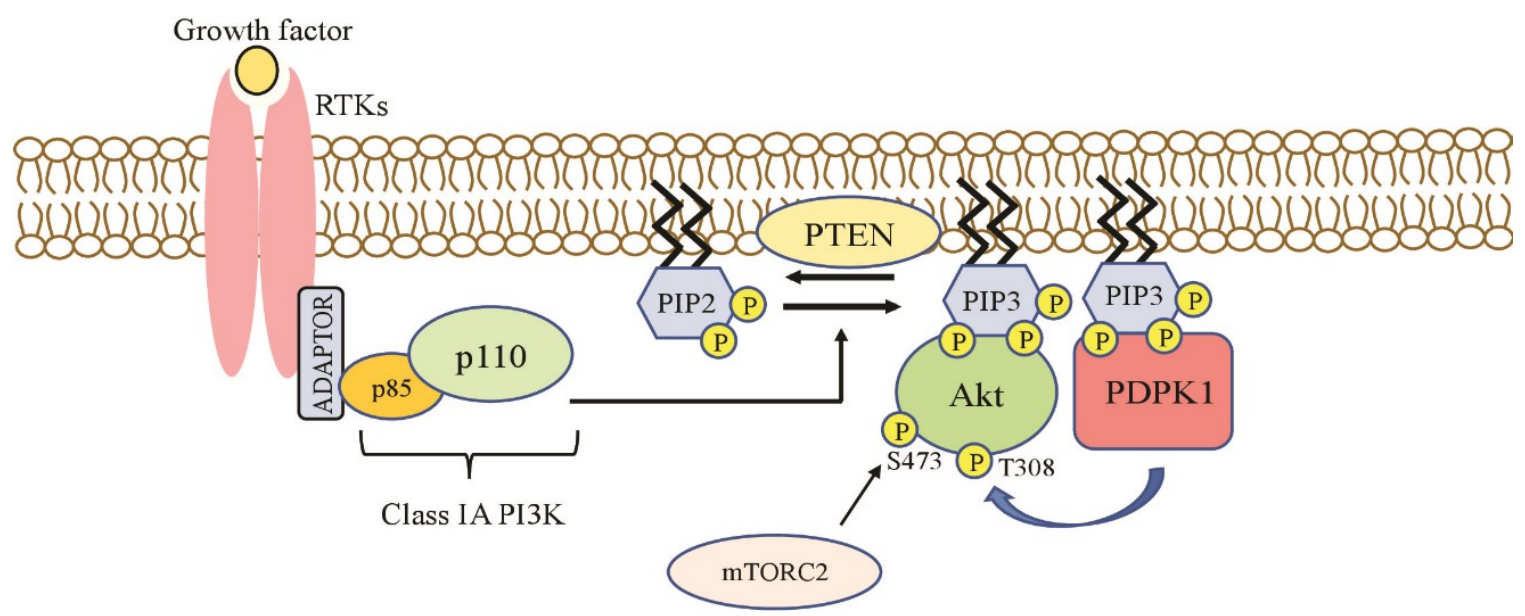

Figure 1-1 Canonical activation of class IA PI3K by RTKs.

Growth factor binds and activates its respective receptor tyrosine kinase (RTK). Activated RTK (e.g. FGFR, HER2, EGFR) recruits and phosphorylates an adaptor protein which in turn recruits class IA PI3K via binding the N-terminal SH2 domain of its p85 regulatory subunit. Activated RTK (e.g. PDGFR) can also directly bind the p85 subunit (not shown). Binding of the $\mathrm{p} 85$ regulatory subunit relieves its allosteric inhibition on the p110 catalytic subunit. Active PI3K catalyzes the phosphorylation of PIP2 to PIP3. The second messenger PIP3 recruits Akt and PDPK1 to the membrane via their respective pleckstrin homology domain. PDPK1 phosphorylates T308 of Akt and mammalian target of rapamycin complex 2 (mTORC2) phosphorylates S473 of Akt, resulting in full activation of Akt. The tumor suppressor PTEN negatively regulates PI3K signaling by catalyzing the dephosphorylation of PIP3 back to PIP2. 
the allosteric inhibition of the p85 regulatory subunit on the p110 catalytic subunit (42). PIP2 is then phosphorylated by the p110 subunit to produce the second messenger phosphatidylinositol-3,4,5-triphosphate (PIP3). PTEN dephosphorylates PIP3 at the 3' position of the inositol ring and is thus a vital negative regulator of PI3K signaling (43).

PIP3 recruits Akt and phosphoinositide-dependent protein kinase 1 (PDPK1) to the membrane via their respective pleckstrin homology domain (1). The subsequent phosphorylation of Akt at T308 by PDPK1 and at S473 by mTORC2 results in full activation of Akt (44). Akt phosphorylates multiple important downstream targets including glycogen synthase kinase 3 beta (GSK3 $\beta$ ), forkhead box(Fox)O transcription factors, mouse double minute 2 homolog (Mdm2), Bcl-2-associated death promoter (BAD) and p27 ${ }^{\mathrm{KIP} 1}$, together promoting survival and cell cycle entry (45). Akt also phosphorylates Tuberin, a guanosine triphosphate(GTP)ase-activating protein (GAP) for Ras homologue enriched in brain (Rheb). Phosphorylation of Tuberin results in its inactivation, allowing for GTP-bound Rheb to activate $\mathrm{mTORC} 1$ which regulates protein synthesis, RNA translation, cell growth and autophagy (46). In this manner, the $\mathrm{PI} 3 \mathrm{~K} / \mathrm{Akt} / \mathrm{mTORC} 1$ axis controls a diverse array of cellular processes and its overactivation in tumor cells confers a significant growth and survival advantage.

The PI3K/Akt/mTORC1 pathway is one of the most commonly altered signaling pathways in human cancer. Such alterations leading to increased activity of the pathway in tumor cells include loss of the tumor suppressor PTEN as well as mutation and/or amplification of p110 and p85 subunits; RTKs such as HER2, FGFR, EGFR; the PI3K interactor and activator Ras; and the PI3K effector Akt (44). Mutational loss or deletion of PTEN occurs in a diverse array of human cancers (40) and predictably mediates an increase in PI3K signaling in PTEN-null tumor cell lines and primary tumors (47). The most common alterations of the pathway however occur within the helical domain (E542K and E545K) and kinase domain (H1047R) of p1 10 $\alpha$ (44). Helical domain mutations increase PI3K activity by diminishing the allosteric inhibition of $\mathrm{p} 85$ on the p110 $\alpha$ subunit (48) or increasing interaction between $\mathrm{p} 110 \alpha$ and insulin receptor substrate 1 (IRS-1) (49), while mutations in the kinase domain increase retention of p1 $10 \alpha$ at the plasma membrane (50). Like helical domain alterations, mutations in p85 reduce its ability to inhibit the p110 catalytic subunit $(51,52)$. As the canonical signaling through RTKs occurs through PI3K, the overexpression or constitutive activation of oncogenic RTKs such as HER2, FGFR, EGFR results in constant activation of the $\mathrm{PI} 3 \mathrm{~K} / \mathrm{Akt} / \mathrm{mTORC} 1$ pathway. Similarly, PI3K is activated canonically by Ras through direct binding to its Ras-binding domain and oncogenic overexpression of Ras results in constitutive PI3K activation. Regardless of the mechanism, hyperactivation of the pathway results in a significant advantage to tumor cells, promoting cell growth, division, protein synthesis and survival. In addition, the PI3K/Akt/mTORC1 pathway plays a major role in the metabolic rewiring observed in tumor cells.

The PI3K/Akt/mTORC1 pathway, under physiological activation by growth factors, mediates an important shift in the cell's metabolic profile to an anabolic one. This allows the cell to coordinate its cellular metabolism to support bioenergetically demanding processes stimulated by growth factors. However, when constitutively 
activated, the same downstream metabolic effects, as well as cancer specific ones, contribute to the altered metabolism observed in tumor cells. The PI3K effector Akt increases glucose transporter localization to the membrane (53) and phosphorylates HK2, increasing its activity (54). Akt also phosphorylates phosphofructokinase-2 (PFK2), enhancing its activity and increasing the levels of phosphofructo-2,6-bisphosphate, a potent allosteric activator of the key glycolytic enzyme PFK1 (55). As described above, Akt activates the downstream serine/threonine kinase mTORC1 complex. mTORC1 induces expression of HIFs (56) which increase glycolytic flux as described in the previous section.

Additionally, the upregulation of pyruvate kinase muscle isozyme 2 (PKM2) by mTORC1 is essential to aerobic glycolysis and tumor growth and occurs via its induction of HIF1 and Myc (57). There are two isoforms of M type pyruvate kinase which catalyze the dephosphorylation of phosphoenolpyruvate to pyruvate in the last step of glycolysis. While PKM1 is expressed in most terminally differentiated tissues, PKM2 is expressed in embryonic and proliferating tissues which require anabolic biosynthesis (15). The switch from oxidative phosphorylation to aerobic glycolysis in cancer cells reflects a shift from PKM1 to PKM2 expression (58) as the PKM2 exists in its inactive dimeric form in tumor cells, allowing for the accumulation of glycolytic intermediates for their use in biosynthesis (59) and entry into the pentose phosphate pathway (discussed in the next section). In this manner, constitutive activation of the PI3K/Akt $/ \mathrm{mTORC} 1$ pathway contributes significantly to the metabolic rewiring observed in tumor cells while concomitantly promoting protein synthesis, cell growth, survival and division.

As one of the most commonly mutated signaling pathways across all human cancers, the PI3K/Akt/mTORC1 pathway controls a diverse array of essential cellular functions and thus is an important focus of current drug research. Excessive signaling through the pathway mediates the altered glycolytic metabolism observed in tumor cells, and as discussed in the next chapter, also facilitates an upregulation of the closely linked pentose phosphate pathway.

\section{The Pentose Phosphate Pathway and Cancer}

The pentose phosphate pathway (PPP) is a glucose catabolic pathway, tightly linked to glycolysis, that generates NADPH and ribose-5-phosphate (R5P) (Figure 1-2) and is upregulated in tumor cells. Glucose upon entering the cell is phosphorylated by hexokinase to glucose-6-phosphate (G6P) which can be further metabolized by glycolysis. G6P can also be dehydrogenated by glucose-6-phosphate dehydrogenase (G6PD) and enter the pentose phosphate pathway. The PPP is comprised of oxidative and nonoxidative branches. The former catalyzes the irreversible conversion of G6P to R5P and produces 2 molecules of NADPH in the process. NADPH is an important molecule necessary for reductive biosynthesis reactions and functions as a key reducing agent to counteract reactive oxygen species (ROS). R5P, a precursor to various biomolecules including nucleotides, can enter the nonoxidative, reversible branch of the PPP and be 


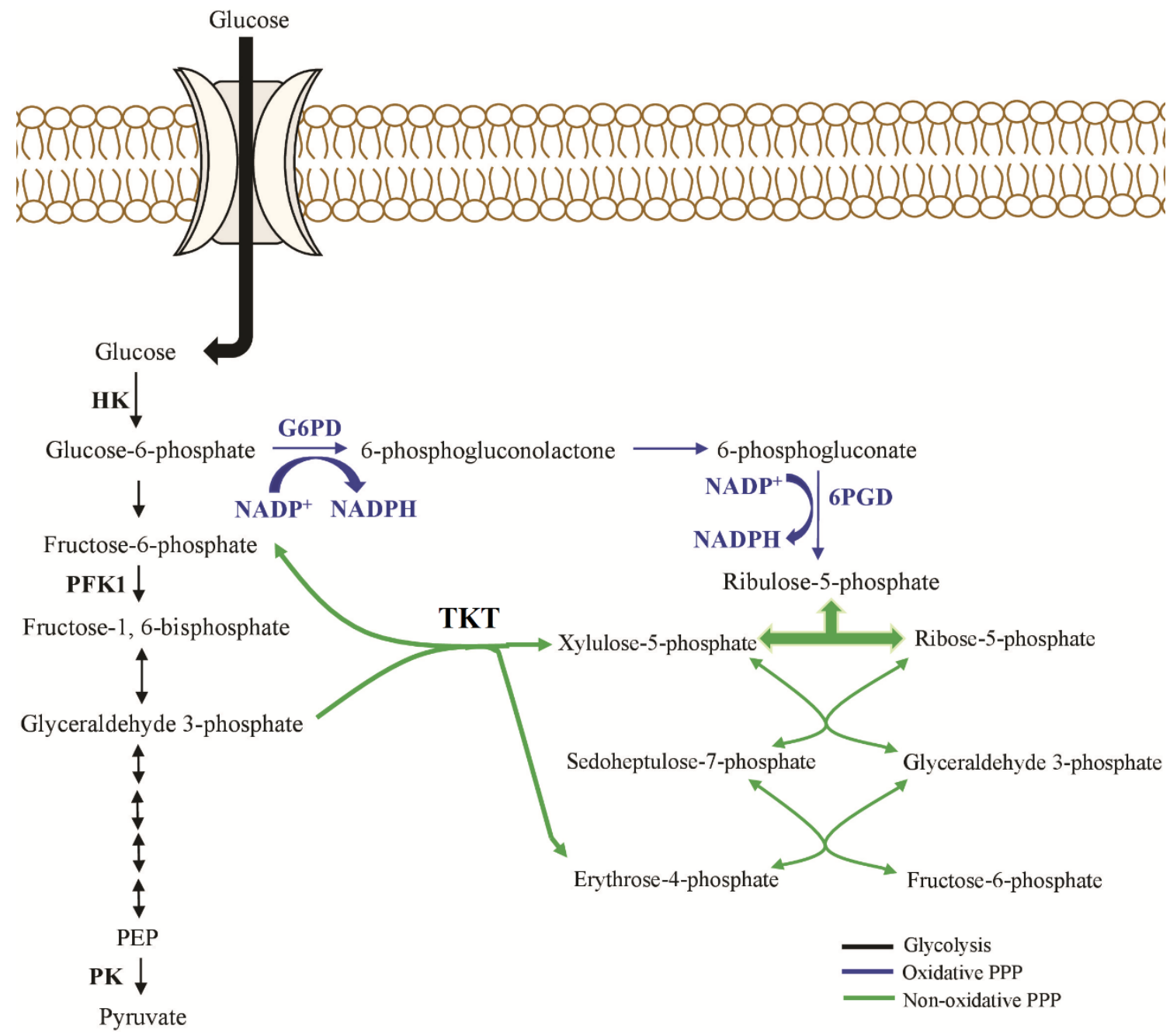

Figure 1-2. Glycolysis and the pentose phosphate pathway are tightly linked glucose catabolic pathways.

Glucose enters the cell via a glucose transporter and is subsequently phosphorylated by hexokinase (HK) to glucose-6-phosphate (G6P). G6P can be further catabolized by the glycolytic pathway (black arrows). G6P can also enter the oxidative arm of the PPP, which generates NADPH, an important biomolecule necessary for reductive biosynthesis and to counteract reactive oxygen species. The oxidative arm of the PPP generates ribulose-5-phosphate which can then enter the non-oxidative arm of the PPP to generate other intermediate biomolecules including the ribose-5-phosphate, a necessary precursor for nucleotide synthesis. As shown, the glycolytic and pentose phosphate pathways are tightly linked as glycolytic intermediates can enter the PPP and vice versa.

Abbreviations: phosphofructokinase-1 (PFK1), pyruvate kinase (PK), glucose-6phosphate dehydrogenase (G6PD), transketolase (TKT). 
converted into the glycolytic intermediates glyceraldehyde 3-phosphate (G3P) and fructose-6-phosphate (F6P). In this manner, glycolysis and the PPP are coordinated to meet the metabolic demands of the cell. Under oxidative stress, when greater levels of $\mathrm{NADPH}$ are required, R5P can be converted to G3P and F6P which in turn can be used to generate G6P (via gluconeogenic pathways) feeding the oxidative arm of the PPP and generating reductive NADPH (5). Likewise, the glycolytic intermediates G3P and F6P can enter the nonoxidative branch to generate R5P for nucleotide synthesis. Like glycolysis, higher PPP flux has been observed in various human cancers (5) and plays an important role in tumor proliferation, survival, invasion, drug resistance and metastasis (60). An increase in PPP flux supports the biogenesis of nucleotides while also generating NADPH necessary to synthesize lipids and other biomolecules as well as to counteract the high ROS present in tumor cells.

The PPP is frequently upregulated in various human cancers (60) and is presumably mediated by genetic alterations in the tumor suppressors p53 and PTEN and the oncogenic PI3K/Akt/mTORC1 activation. As the first and rate-limiting enzyme of the PPP, G6PD determines PPP flux and the upregulation of its expression and activity supports the bioenergetic demands of proliferating cancer cells (5). G6PD exists in either an inactive monomeric or active dimeric form. The tumor suppressor $\mathrm{p} 53$ has been previously shown to directly bind G6PD and prevent its dimerization while a cancerassociated mutation of p53 was unable to inhibit G6PD activity (61). The oncogene KRas stimulates glycolysis and drives glycolytic intermediates into the nonoxidative arm of the PPP in pancreatic ductal adenocarcinoma (62). The transcription factor HIF1 in addition to its upregulation of glycolytic enzymes also enhances G6PD expression (63). The PI3K/Akt downstream effector mTORC1 has also been shown to increase G6PD expression via induction of sterol regulatory element-binding protein (SREBP) transcription factors (56). The tumor suppressor PTEN, which negatively regulates PI3K signaling, appears to also have a role in suppressing G6PD activity (64). The loss of PTEN which occurs in a diverse array of tumors would therefore predictably increase PPP flux.

Collectively, the progressive accumulation of such genetic alterations that mediate the transformation of a normal cell to a cancerous one facilitate an altered metabolic phenotype characterized by increased aerobic glycolysis and PPP flux. Together, the upregulation of these glucose catabolic pathways provides energy and important intermediates to support the biogenesis required for rapid growth and proliferation. We hypothesize here that the altered metabolism of cancer cells not only provides precursors for anabolic biomass accumulation, but also generates signaling metabolites that regulate key cellular processes to further promote tumor growth and survival. Described in the next section, we have previously identified a novel metabolic regulation of apoptosis mediated by increased PPP flux generating coenzyme A, a novel signaling metabolite in our model. 


\section{Metabolic Regulation of Programmed Cell Death}

Studying altered metabolism in mammalian cells is cumbersome given the impermeability of most intermediate metabolites. The Xenopus oocyte system however has been shown by our group and suggested by others to be a more biochemically tractable model system providing insights into tumor cell metabolism $(59,65)$. Indeed, the metabolism of the Xenopus oocyte shares interesting similarities with the altered metabolism of tumor cells including increased lactate production, similar PK activity, the use of glutamine as a carbon source, and flux through the pentose phosphate pathway (59).

Using this biochemically robust model system, we have characterized a novel metabolic regulation of cell death mediated by increased flux through the PPP. G6P addition to Xenopus extract, mimicking aberrant glucose metabolism, via the pentose phosphate pathway leads to increased NADPH levels, subsequent increase in cytosolic acetyl-CoA and CaMKII activation (66-69). CaMKII in turn phosphorylates and inhibits caspase-2, blocking apoptosis. We recently identified coenzyme A, derived from the breakdown of acetyl CoA, as the key signaling metabolite that mediates a novel mechanism of metabolic activation of CaMKII (Figure 1-3). CoA binds directly to the regulatory CaMBD of CaMKII resulting in its activation (67). With these findings, we hypothesize that the altered concentration of acetyl CoA and CoA, generated by aberrant metabolism, contributes to the pathological activation of CaM-dependent enzymes contributing to diseases. To test this, we first took an unbiased approach to purify CaMbinding proteins from Xenopus extract using a CaM-Sepharose column. Purified proteins were concentrated and next incubated with CoA-Sepharose, resolved by SDS-PAGE and silver staining. The results indicate the presence of multiple CaM-binding proteins that also bind CoA and are potentially metabolically regulated by aberrant glucose signaling. In a targeted approach, we tested the metabolic regulation of the CaM-binding protein PI3K. We found that G6P or CoA addition to Xenopus extract activated Akt in a PI3K and PDPK-1 dependent manner. Furthermore, we show that CoA directly binds and activates PI3K. These findings suggest a novel function for calmodulin binding proteins regulated by metabolism through $\mathrm{CoA}$ binding and uncover a potentially unknown mechanism of constitutive activation of PI3K by aberrant glucose metabolism in tumor cells. 


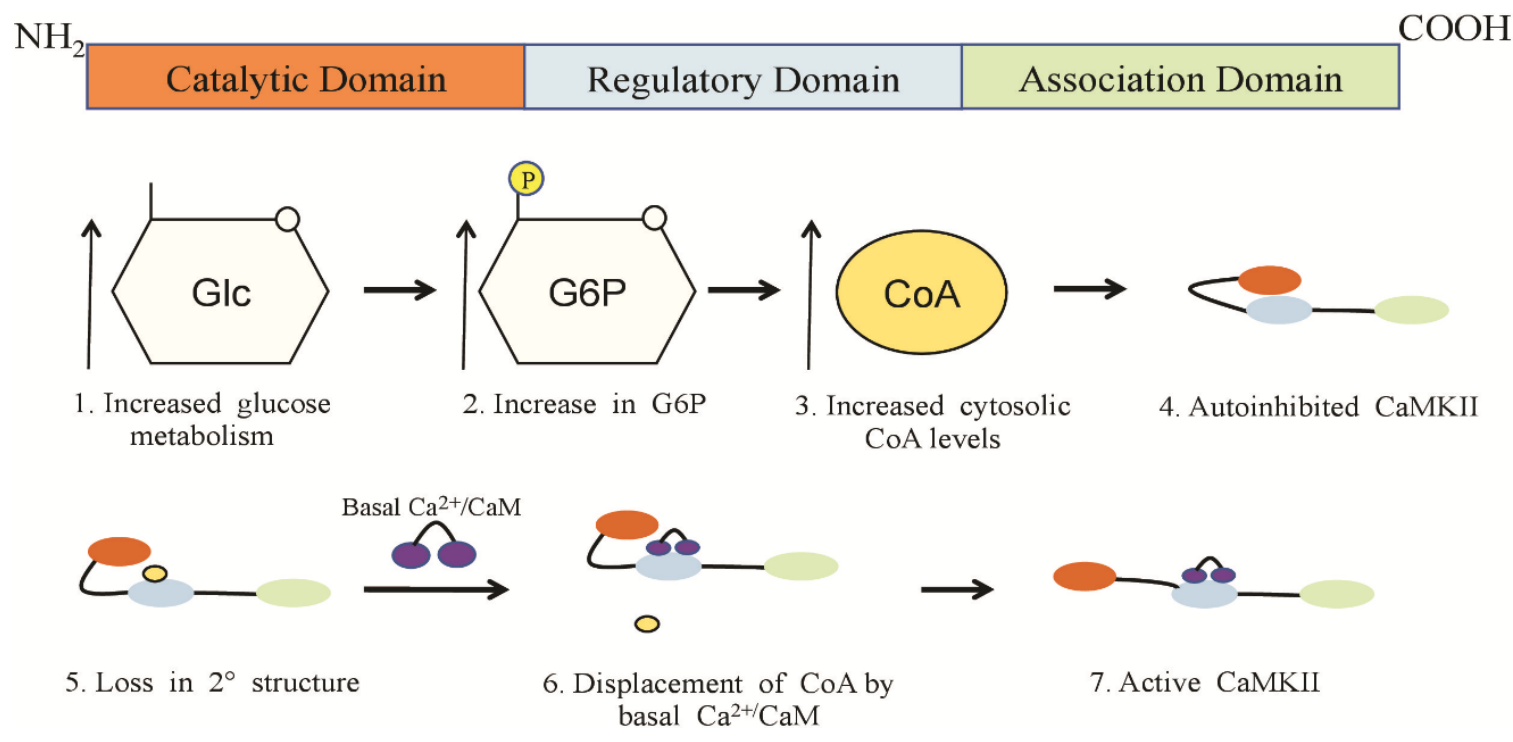

Figure 1-3. A model of the noncanonical activation of CaMKII by altered glucose signaling.

We have previously characterized a novel metabolic activation of CaMKII. Aberrant glucose metabolism leads to an increase in G6P which via the pentose phosphate pathway and increased NADPH levels, leads to an increase in cytosolic CoA levels. CoA, as a novel signaling metabolite in our model, binds directly to the CaMBD within the regulatory domain of CaMKII, resulting in a loss of secondary structure. Basal (nanomolar) $\mathrm{Ca}^{2+} / \mathrm{CaM}$ is then able to bind the CaMBD of CaMKII, displacing CoA and resulting in CaMKII autophosphorylation and activation. 


\section{CHAPTER 2. MATERIALS AND METHODS}

\section{Reagents}

Reagents were used as previously described (66-68). CaM-Sepharose was purchased from GE Healthcare Life Sciences (Cat \#17052901). CaM column was made by packing CaM-Sepharose in a BioRad poly-prep chromatography column (Cat \#7311550) to a final, packed bead volume of $1 \mathrm{~mL}$. Purified CaM proteins from the column were concentrated and buffer exchanged using a 10K Ultra-15 centrifugal filter (Amicon, Cat \#UFC501096). Recombinant p110 $\beta / \mathrm{p} 85 \alpha$ was purchased from SigmaAldrich (Cat \#I1036). Extract was supplemented with phosophatidylinositol polyphosphates purchased from Echelon Biosciences Inc: D-myo-Phosphatidylinositol4,5-bisphosphate diC16 (PIP2-16) (Cat \#P-4516), D-myo-Phosphatidylinositol-3,4,5trisphosphate diC16 (PIP3-16) (Cat \#P-3916), or D-myo-Phosphatidylinositol-4,5bisphosphate diC8 (PIP2-8) (Cat \#P-4508).

D-myo-Phosphatidylinositol 4,5-bisphosphate 18:0/20:4 (Echelon Biosciences Inc, Cat \#P-4524) was used as substrate in the PI3K thin-layer chromatography (TLC) assays. D-myo-Phosphatidylinositol 3,4,5-triphosphate 18:0/20:4 (Echelon Biosciences Inc, Cat \#P-3924) was used as a standard in the PI3K TLC assays as the unsaturated fatty acid allows for identification by iodine vapor exposure. Wortmannin (Cat \#10010591) and LY-294002 (LY) (Cat \#70920) were purchased from Cayman Chemical. GSK2334470 (GSK) was purchased from AdooQ BioScience (Cat \#A12767).

\section{Antibodies}

Calcium/calmodulin-dependent protein kinase IV (CaMKIV) rabbit polyclonal antibody with dog $(\mathrm{Dg})$, human $(\mathrm{H})$, mouse $(\mathrm{M})$, Xenopus $(\mathrm{X})$ reactivity was purchased from ThermoFisher Scientific Pierce (Cat \#PA1-542, Lot \#NE170396). CaMKII mouse monoclonal antibody with $\mathrm{H}, \mathrm{M}, \mathrm{Dg}, \mathrm{X}$ reactivity was purchased from BD Biosciences (Cat \#611292, Lot \#5037692). PI3K p110ß rabbit monoclonal antibody, H specificity (Cat \#3011, Lot \#6), p-T308-Akt rabbit polyclonal antibody, M specificity with cross reactivity against $H$, rabbit $(\mathrm{R})$, hamster (Hm) (Cat \#9275, Lot \#'s 20, 21), p-S473-Akt rabbit polyclonal antibody, $M$ specificity with cross reactivity against $\mathrm{H}, \mathrm{R}$, pig $(\mathrm{Pg})$, Hm, bovine (B), Drosophila melanogaster (Dm), Dg, monkey (Mk), chicken (C), horse (Hr), X (Cat \#9271, Lot \#14) were purchased from Cell Signaling Technology. Calcineurin A rabbit polyclonal antibody with $\mathrm{H}, \mathrm{M}, \mathrm{X}$ reactivity (Cat \#ab71149), Akt $1 / 2 / 3$ rabbit polyclonal antibody, $H$ specificity with cross reactivity against $M, R$ (Cat \#ab126811), glyceraldehyde 3-phosphate dehydrogenase (GAPDH) mouse monoclonal antibody, $\mathrm{H}$ specificity with cross reactivity against $\mathrm{M}, \mathrm{R}, \mathrm{C}, \mathrm{B}, \mathrm{Dg}, \mathrm{Pg}, \mathrm{X}, \mathrm{Hm}$ (Cat \#9484, Lot \#GR165366-1), and actin rabbit polyclonal antibody, H specificity with cross reactivity against $\mathrm{M}, \mathrm{R}, \mathrm{C}, \mathrm{B}, \mathrm{X}, \mathrm{Dm}$ (Cat \#ab1801) were purchased from Abcam. $\mathrm{P} 110 \alpha$ rabbit polyclonal antibody, $\mathrm{H}$ specificity with cross reactivity against $\mathrm{M}, \mathrm{R}, \mathrm{X}$, $\mathrm{Hr}, \mathrm{Dg}, \mathrm{B}$ (Cat \#7174, Lot \#G0214) and p85 $\alpha$ rabbit polyclonal, H specificity with 
cross reactivity against $\mathrm{M}, \mathrm{R}, \mathrm{X}, \mathrm{Hr}, \mathrm{Dg}, \mathrm{B}, \mathrm{Pg}$ (Cat \#423, Lot \#G1114) were purchased from Santa Cruz Biotechnology.

\section{Preparation of Xenopus Extract and Extract Cytosol}

Mature female Xenopus laevis frogs were induced to lay eggs as previously described (70). Egg extracts and extract cytosol were prepared as previously described (68).

\section{Peptide Synthesis and Sepharose Coupling}

All peptide synthesis and coupling was performed by the Macromolecular Synthesis Laboratory Core at St. Jude Children's Research Hospital. For the tandem purification described in Chapter 3, CoA was coupled to Sepharose via the primary amine on the adenine ring. Phospho-tyrosine peptide [KKHTDDGY*MPMSPGVA] (pIRS), derived from mouse insulin receptor substrate 1 (IRS1), was synthesized and coupled covalently to Sepharose 4B at its NH2 terminus via a hexanoic acid linker. In Chapter 4, CoA was coupled to Affi-Gel 15 via the primary amine on the adenine ring. Glycine was coupled to Affi-Gel 15 and used as Affi-Gel 15 control beads where indicated.

\section{CoA/CaM Tandem Purification}

$\mathrm{CaM} / \mathrm{CoA}$ interactors were purified from Xenopus extract as follows (Figure 2-1). CaM-Sepharose was packed in a chromatography column (BioRad Cat \#731-1550) to a final bead volume of 1 milliliter $(\mathrm{mL})$. The CaM column was equilibrated with 50 millimolar (mM) tris(hydroxymethyl)aminomethane-hydrochloric acid (Tris- $\mathrm{HCl}) \mathrm{pH} 7.5$ containing $150 \mathrm{mM}$ sodium chloride $(\mathrm{NaCl})$, and $2 \mathrm{mM}$ calcium chloride $\left(\mathrm{CaCl}_{2}\right)$.

Xenopus egg extract was then bound to the column by gravity flow and washed with 50 mM 4-(2-hydroxyethyl)-1-piperazineethanesulfonic acid (HEPES) pH 7.5 containing 1 $\mathrm{mM}$ magnesium acetate $(\mathrm{MgAc}), 1$ molar $(\mathrm{M}) \mathrm{NaCl}$, and $1 \mathrm{mM} \mathrm{CaCl}_{2}$. A second wash was then performed with $50 \mathrm{mM}$ HEPES pH 7.5, $1 \mathrm{mM} \mathrm{MgAc}, 150 \mathrm{mM} \mathrm{NaCl}$ and 500 micromolar $(\mu \mathrm{M}) \mathrm{CaCl}_{2}$. Proteins were eluted with $20 \mathrm{mM}$ ethylene glycol-bis $(\beta-$ aminoethyl ether)-N,N,N',N'-tetraacetic acid (EGTA), $1 \mathrm{M} \mathrm{NaCl}$ in $50 \mathrm{mM}$ HEPES pH 7.5. The column was regenerated with $50 \mathrm{mM}$ Tris- $\mathrm{HCl} \mathrm{pH} \mathrm{7.5,} 1 \mathrm{M} \mathrm{NaCl}$ and .1\% triton, heated to 37 degrees Celsius, and stored in equilibration buffer containing $20 \%$ ethanol preservative. Eluted proteins were concentrated, buffer exchanged with $50 \mathrm{mM}$ HEPES $\mathrm{pH} 7.5$, and incubated with either CoA-Sepharose or Sepharose for 30 minutes at room temperature. Beads were washed, resolved by SDS-PAGE and either immunoblotted (along with samples of elution fractions) for CaMKII or silver stained.

Silver staining was performed by first fixing the SDS-PAGE gel in $10 \%$ acetic acid/ $30 \%$ ethanol for 2 hours. The gel was then rinsed with $20 \%$ ethanol for 20 minutes, 


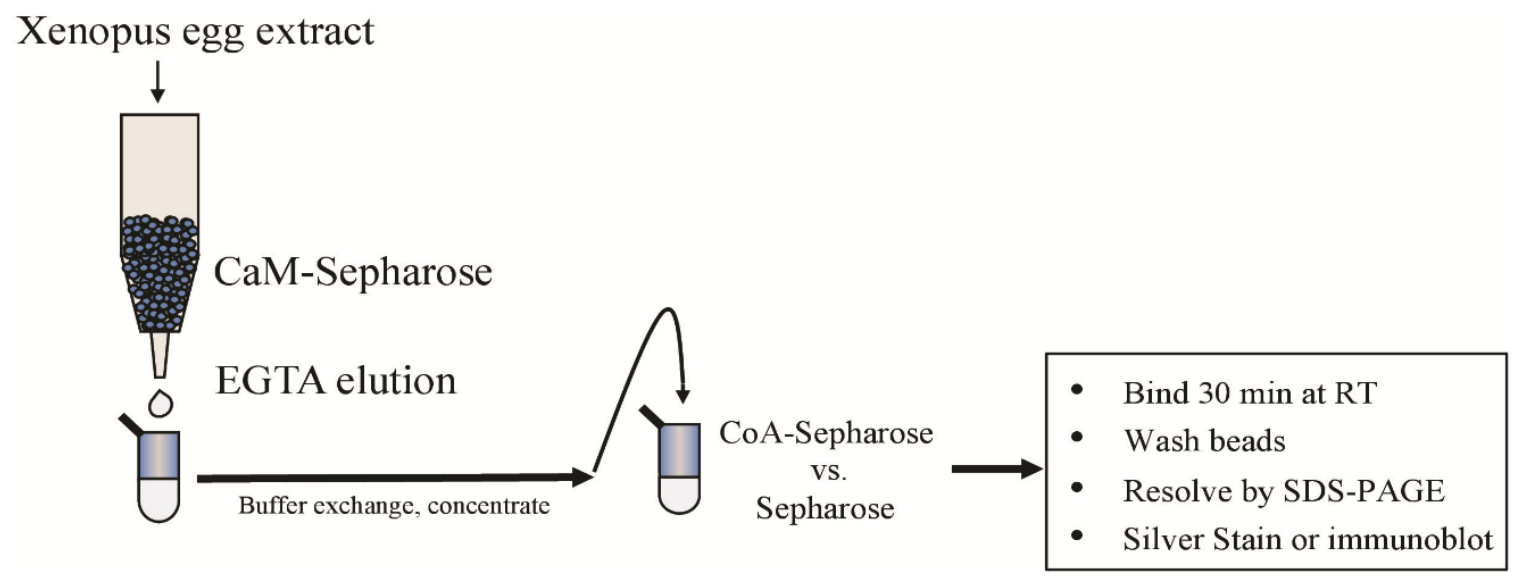

Figure 2-1. Tandem purification of CaM/CoA binding proteins from Xenopus egg extract.

Xenopus egg extract was bound to a CaM-Sepharose column by gravity flow, washed and eluted with EGTA. Purified CaM-binding proteins were concentrated, buffer exchanged, and incubated with either CoA-Sepharose or Sepharose for 30 minutes at room temperature (RT) and resolved by SDS-PAGE. Gels were then either immunoblotted for the known $\mathrm{CoA} / \mathrm{CaM}$ interactor CaMKII or silver stained. 
ouble distilled water $\left(\mathrm{ddH}_{2} \mathrm{O}\right)$ for 10 minutes and then incubated with .2 gram $(\mathrm{g}) /$ liter (L) sodium thiosulfate for 1 minute. After washing three times with $\mathrm{ddH}_{2} \mathrm{O}$ for 20 seconds, $2 \mathrm{~g} / \mathrm{L}$ silver nitrate was added for 45 minutes, followed by 5 rinses with $\mathrm{ddH}_{2} \mathrm{O}$ for 10 seconds each. Proteins were visualized by developing with $50 \mathrm{~g} / \mathrm{L}$ sodium carbonate, $10 \mathrm{mg} / \mathrm{L}$ sodium thiosulfate, $.25 \mathrm{~mL} / \mathrm{L} 37 \%$ formaldehyde. Silver staining was stopped by adding $50 \mathrm{~g} / \mathrm{L}$ Tris-base, $2.5 \%$ acetic acid and subsequently washed with $\mathrm{ddH}_{2} \mathrm{O}$.

\section{PI3K TLC Assays and Spot Quantification}

Direct PI3K thin layer chromatography (TLC) assays were performed as previously described (71) using $14 \mathrm{nM}$ recombinant $\mathrm{p} 110 \beta / \mathrm{p} 85 \alpha$ in $50 \mathrm{mM}$ HEPES buffer with $5 \mathrm{mM}$ magnesium chloride $\left(\mathrm{MgCl}_{2}\right), 100 \mu \mathrm{M}$ ATP, $24 \mathrm{ng} / \mu \mathrm{L}$ PIP2 18:0/20:4 and $70 \mathrm{nCi} / \mu \mathrm{L}\left[\gamma^{3}{ }^{32} \mathrm{P}\right] \mathrm{ATP}$. Reactions were run for $20 \mathrm{~min}$ at $\mathrm{RT}$ and resolved by TLC in n-propanol:water:acetic acid (64:33:2, v/v). A TLC assay was similarly performed using extract cytosol supplemented with $100 \mathrm{ng} / \mathrm{uL}$ PIP2 18:0/20:4, G6P with and without Wortmannin or LY. Samples were resolved by TLC in chloroform:methanol:water:acetic acid (10:10:3:1, v/v). Spot intensities were quantified using imageJ (72). Briefly, film exposures from independent experiments and within a linear range of exposure were scanned, adjusted to grayscale, and opened with imageJ. The rectangular tool was used to encompass radiograph spots, assigned by pressing [Ctrl+1], then spot intensities were plotted by pressing $[\mathrm{Ctrl}+3]$, peaks were isolated using the line segment tool, the area under each peak was measured using the wand (tracing) tool and each divided by the corresponding control (PI3K alone) area for each independent experiment. Averages across the experiments were plotted with standard deviation error bars. Statistical analysis was performed using paired t-test of each treatment compared to the corresponding PI3K alone control.

\section{Depletions of Egg Extract and Coupled-Sepharose Binding Assays}

Depletions of egg extract and affinity binding assays were performed as described previously $(66,68)$. PI3K in vitro affinity binding assays were performed by incubating CaM-Sepharose, pIRS-Sepharose, Sepharose alone, CoA-coupled Affi-Gel 15 or AffiGel 15 control beads in $50 \mathrm{mM}$ Hepes buffer with $14 \mathrm{nM}$ recombinant $\mathrm{p} 110 \beta / \mathrm{p} 85 \alpha$ for 30 minutes at RT. Beads were washed 5 times with $1 \mathrm{~mL}$ of $500 \mathrm{mM} \mathrm{NaCl} / .5 \%$ triton, resolved by SDS-PAGE and immunoblotted for $\mathrm{p} 110 \beta$.

\section{HeLa Cell Cytosol Binding Assay}

HeLa S3 cells, derived from human cervical adenocarcinoma (ATCC CCL-2.2) were grown to $80 \%$ confluency, trypsinized and homogenized in $20 \mathrm{mM}$ HEPES buffer with $10 \mathrm{mM}$ potassium chloride $(\mathrm{KCl}), 1.5 \mathrm{mM} \mathrm{MgCl}, 1 \mathrm{mM}$ Ethylenediaminetetraacetic acid (EDTA), $1 \mathrm{mM}$ EGTA and $250 \mathrm{mM}$ sucrose. Cells were pelleted and supernatant 
removed. Equal volume of cell cytosol was then used in a CoA-Affi-Gel binding assay as described above. 


\section{CHAPTER 3. IDENTIFICATION OF NOVEL COA/CAM INTERACTORS}

\section{Introduction}

Calmodulin binding proteins represent a diverse array of proteins involved in major cellular processes including metabolism, muscle contraction, cell death, memory and inflammation (73). We have previously characterized a novel metabolic activation of $\mathrm{Ca}^{2+} /$ calmodulin-dependent protein kinase II (CaMKII) mediated by direct CoA binding to its CaMBD (67). In our model, direct CoA binding results in a loss of secondary structure in CaMKII, facilitating basal (nanomolar) $\mathrm{Ca}^{2+} / \mathrm{CaM}$ binding and subsequent CaMKII autophosphorylation and activation (Figure 1-3). Given the great number of $\mathrm{CaM}$ interacting proteins that exist, we asked here if there are other CaM-binding proteins that also bind $\mathrm{CoA}$ and are thus potentially regulated by altered metabolic signaling.

$\mathrm{CaM}$ is a relatively small, approximately 17 kilodalton ( $\mathrm{kDA}), \alpha$-helical protein comprised of $\mathrm{N}$ - and $\mathrm{C}$-terminal lobes connected by a highly dynamic and flexible linker (74). While both lobes each contain two $\mathrm{Ca}^{2+}$ binding EF-hand motifs, the $\mathrm{C}$-terminal lobe coordinates $\mathrm{Ca}^{2+}$ with a 10 -fold greater affinity $\left(K_{\mathrm{d}}=1 \mu \mathrm{M}\right)$ as compared to the Nterminal lobe $\left(K_{\mathrm{d}}=10 \mu \mathrm{M}\right)(75,76)$. Given this and the $\mathrm{Ca}^{2+}$ cooperativity that exists both within and between its lobes, CaM has evolved to respond over a wide range of changes in cellular calcium concentrations (74). Upon $\mathrm{Ca}^{2+}$ binding, conformational changes in $\mathrm{CaM}$ expose hydrophobic patches in each lobe that facilitate binding to key hydrophobic residues in the CaMBD of target proteins (74). The large number of flexible methionine residues within these hydrophobic patches, in combination with the dynamic linker connecting the two lobes, allows for $\mathrm{CaM}$ to interact with a diverse set of proteins (77).

While a defined CaM-binding consensus sequence does not exist, $\mathrm{Ca}^{2+} / \mathrm{CaM}-$ binding sequences share important similarities including high helix propensity, a high density of positively charged residues and two hydrophobic anchor residues (73). The spacing of these two key hydrophobic residues within the approximately 20 amino acid CaM-binding domain allows for the classification of $\mathrm{Ca}^{2+} / \mathrm{CaM}$-binding proteins into three groups (1-10, 1-14, and 1-16) (78). Adding to the complexity, CaM can bind its target proteins in either a parallel or anti-parallel orientation, depending on the charge density of the binding motif (77). Furthermore, $\mathrm{CaM}$ also interacts with target proteins in the absence of calcium via binding to the IQ motif (IQXXXRGXXXR) (75). Given this dynamic and promiscuous nature of its binding, $\mathrm{CaM}$ has been reported to bind over 300 proteins (79-81).

Given our previous results demonstrating that CoA directly binds to the CaMBD of CaMKII, a 1-10 CaM-binding protein, we asked here if there exist other CaM-binding proteins that also bind $\mathrm{CoA}$ and are thus potential targets of aberrant glucose signaling. In an unbiased, tandem purification approach, we identify the presence of numerous CaM- 
binding proteins that also bind CoA. These findings suggest a ubiquitous function for calmodulin binding proteins that also bind $\mathrm{CoA}$ and facilitate their metabolic regulation.

\section{Results}

\section{CaM-binding proteins are efficiently purified from Xenopus extract}

Given its high binding affinity and specificity for $\mathrm{Ca}^{2+} / \mathrm{CaM}$, the CaMBD is classically used in combination with the calcium chelator EGTA to efficiently purify recombinantly expressed CaMBD-tagged proteins. Typically, tagged proteins are bound in the presence of calcium to calmodulin resin which is then washed in the presence of calcium and salt to reduce nonspecific binding. Bound proteins are eluted by removing $\mathrm{Ca}^{2+}$ with EGTA. In this manner, unbiased purifications of calmodulin-binding proteins from various cell-based systems have also been performed. Here, we developed a purification of calmodulin-binding proteins from Xenopus egg extract.

The high concentration of proteins $(50-60 \mu \mathrm{g} / \mu \mathrm{L})$ and the ease by which we can generate large volumes by simply injecting a greater number of frogs to lay eggs renders the Xenopus oocyte model system as an ideal one to purify and examine protein-protein interactions. Here, we performed a tandem two-step purification of proteins from Xenopus extract using CaM-Sepharose and CoA-Sepharose (Figure 2-1). Xenopus extract was first bound to a CaM-Sepharose column by gravity flow. Bound proteins were washed and fractions were eluted with EGTA. Samples of fractions were taken, resolved by SDS-PAGE and immunoblotted for CaMKII as a reporter of the two-step purification. CaMKII was effectively eluted in the first five fractions (Figure 3-1A, left lanes). Fractions were combined, protein quantified and incubated with CoA-Sepharose or Sepharose. Beads were isolated, washed, resolved by SDS-PAGE and immunoblotted for CaMKII. Our two-step tandem purification was validated by the ability of CoASepharose to specifically and efficiently bind CaMKII from the pool of proteins eluted off the CaM-Sepharose column (Figure 3-1A, last two lanes). These results verify our developed protocol to purify $\mathrm{CaM} / \mathrm{CoA}$ binding proteins and establish the Xenopus extract as a useful model system to isolate and study CaM-binding proteins.

\section{Numerous CaM-binding proteins exist that also bind $\mathrm{CoA}$}

As a bona fide interactor of both $\mathrm{CaM}$ and $\mathrm{CoA}, \mathrm{CaMKII}$ was used as a reporter and validated our two-step purification described above. To visualize the existence of other $\mathrm{CaM} / \mathrm{CoA}$ interactors, CaM-binding proteins were purified from Xenopus extract, concentrated, quantified and incubated with CoA-Sepharose as described above. Beads were washed, resolved by SDS-PAGE and silver stained. Relying on the reductive precipitation of silver ions complexed with amino acids, silver staining is highly sensitive allowing for the detection of less than $1 \mathrm{ng}$ of protein (82). Here, silver staining revealed 


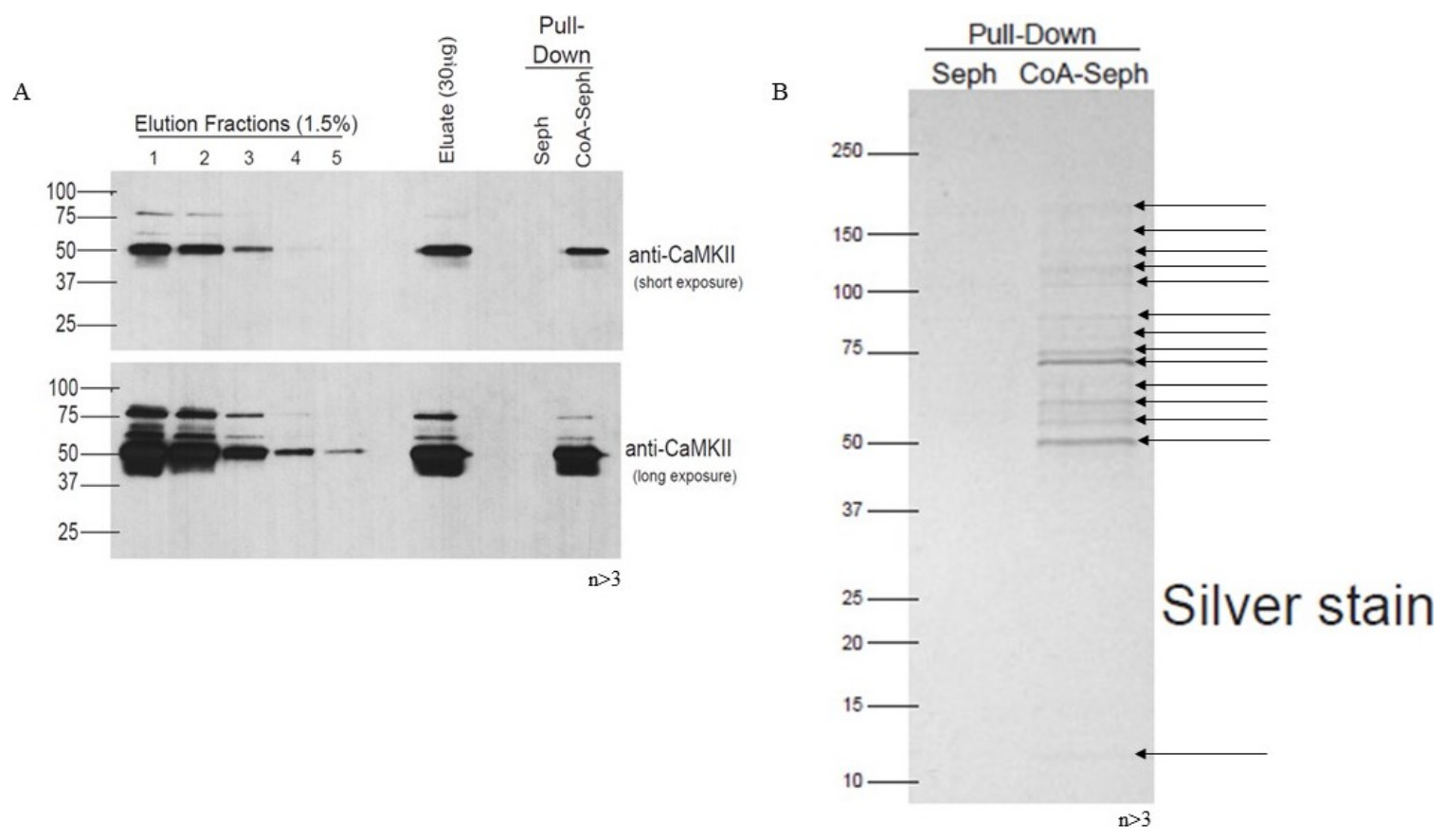

Figure 3-1. Purification of CaM/CoA interactors from Xenopus extract.

A, Xenopus extract was bound to a CaM-Sepharose column, washed, and eluted with EGTA. Fractions were resolved by SDS-PAGE and immunoblotted for CaMKII. Eluted fractions were combined, concentrated, quantified and incubated with either Sepharose or CoA-Sepharose for 30 minutes at RT, washed, resolved by SDS-PAGE and immunblotted for CaMKII. As a reporter of the tandem purification, CaMKII was successfully purified using the CaM-Sepharose column (left lanes) and subsequently effectively precipitated by CoA-Sepharose (last two lanes on right). $n=3$. B, Eluted CaMbinding proteins were incubated with Sepharose or CoA-Sepharose as in A and resolved by SDS-PAGE followed by silver staining. Numerous CaM-binding proteins that also bind $\mathrm{CoA}$ are indicated by black arrows. $\mathrm{n}=3$. 
the existence of numerous CaM-binding proteins that also bind CoA (Figure 3-1B). In combination with our previously delineated model of metabolic activation of CaMKII mediated by direct CoA binding, these results suggest a novel function of CaM-binding proteins that also bind $\mathrm{CoA}$ and facilitate their regulation by altered glucose signaling. 


\section{CHAPTER 4. METABOLIC ACTIVATION OF PHOSPHATIDYLINOSITOL 3- KINASE}

\section{Introduction}

Using the biochemically tractable Xenopus oocyte system, we have previously identified a novel metabolic regulation of pluripotent kinase $\mathrm{Ca}^{2+} /$ calmodulin-dependent kinase II (CaMKII). We found that glucose-6-phosphate (G6P) via the pentose phosphate pathway leads to increased NADPH levels, subsequent increase in cytosolic acetyl CoA and CaMKII activation (66-69). We recently identified coenzyme A (CoA), derived from the breakdown of acetyl CoA, as the key metabolic signal that mediates a novel mechanism of CaM-dependent activation of CaMKII. CoA binds directly to the regulatory calmodulin binding domain of CaMKII resulting in its activation (67). With these findings, we hypothesize that the altered concentration of acetyl CoA and CoA, generated by aberrant metabolic flux, contributes to the pathological activation of CaMdependent enzymes resulting in disease. Analysis of proteins with $\mathrm{CaM}$ binding domains identified phosphatidylinositol 3-kinase (PI3K) as a potentially interesting target of our CoA-dependent, metabolic regulation.

Class IA PI3K is canonically activated by receptor tyrosine kinase (RTK) transmembrane growth factor receptors (Figure 1-1). The phosphorylation of PIP2 to PIP3 by active class IA PI3Ks in the inner leaflet of the plasma membrane concomitantly recruits PDPK1 and Akt to the plasma membrane via their respective pleckstrin homology domain (1). Subsequent PDPK1-dependent phosphorylation of T308-Akt and the mTORC2-dependent phosphorylation of S473-Akt renders Akt fully active (44). With a pivotal role in tumor progression via its regulation of cell metabolism, growth, survival, motility, and differentiation (40), the PI3K/Akt pathway and its constitutive activation in a multitude of human cancers represents an extraordinary focus of cancer research.

Previously published work has shown that PI3K is activated by calmodulin in a calcium-dependent manner (83). Furthermore, a high affinity calmodulin binding sequence, mapped within the p110 catalytic subunit and conserved among the four class I PI3K isoforms with sequence similarities to known calmodulin-binding proteins, was shown to bind calmodulin with a reported affinity constant of $5 \mathrm{nM}(84)$.

In this study, we tested if $\mathrm{PI} 3 \mathrm{~K}$ is metabolically regulated by CoA generated by glucose metabolism. We found that G6P, mimicking aberrant glucose metabolism, or CoA addition to Xenopus laevis egg extracts, activated Akt in a PI3K, PDPK1-dependent manner. Furthermore, we demonstrate that CoA can directly bind as well as directly activate PI3K. These findings uncover a novel mechanism of PI3K activation and a potential link between aberrant glucose metabolism and constitutive activation of $\mathrm{PI} 3 \mathrm{~K} / \mathrm{Akt}$ in tumor cells. 


\section{Results}

\section{CaM directly binds PI3K}

Previously published data identified a calmodulin binding sequence within the p110 catalytic subunit of PI3K. A 20-amino acid peptide derived from this putative CaMBD within the p1 $10 \gamma$ isoform (Figure 4-1A) was shown to bind calmodulin (84). To determine whether CaM interacts with full length PI3K, we developed an affinity precipitation assay. The phospho-tyrosine Y608 peptide [KKHTDDGY*MPMSPGVA] (pIRS), derived from mouse insulin receptor substrate 1 (IRS1), has been previously shown to bind the $\mathrm{SH} 2$ domain of the regulatory $\mathrm{p} 85$ subunit of $\mathrm{PI} 3 \mathrm{~K}$, resulting in activation of the enzyme (85). To establish an affinity precipitation assay for PI3K, pIRS peptide was immobilized on Sepharose and incubated with recombinant $\mathrm{p} 110 \beta / \mathrm{p} 85 \alpha$ PI3K. Figure 4-1A demonstrates that the control pIRS peptide directly interacted with recombinant $\mathrm{PI} 3 \mathrm{~K}$. To confirm that $\mathrm{CaM}$ is a bona fide interactor of $\mathrm{PI} 3 \mathrm{~K}$, we tested whether CaM-Sepharose affinity precipitates PI3K in vitro. While p110 $\gamma$ is exclusively activated downstream of G-protein coupled receptors (GPCRs), the ubiquitously expressed $\mathrm{p} 110 \beta$ isoform has been shown to be activated downstream of both RTKs and GPCRs (13). Given this and the $100 \%$ conservation of key hydrophobic residues within the CaMBD of $\mathrm{p} 110 \alpha, \beta$, and $\delta$ (Figure 4-1A), we chose to look at $110 \beta$ as a representative of class IA PI3Ks. CaM-coupled Sepharose was incubated with recombinant $\mathrm{p} 110 \beta / \mathrm{p} 85 \alpha \mathrm{PI} 3 \mathrm{~K}$, washed and resolved by SDS-PAGE. Figure 4-1B demonstrates that calmodulin directly bound PI3K p110 $\beta / \mathrm{p} 85 \alpha$. Our data both confirm and demonstrate that calmodulin directly binds PI3K.

\section{pIRS (Y608) induces Akt phosphorylation in Xenopus extract}

In the canonical activation of the PI3K signaling cascade by insulin, phosphorylated tyrosine residues within the adaptor protein IRS1 activate PI3K by binding to the $\mathrm{SH} 2$ domain of the regulatory p85 subunit, releasing its allosteric inhibition on the p1 10 catalytic subunit (86). Active PI3K then phosphorylates PIP2 to PIP3 which recruits PDPK1 and Akt via their respective pleckstrin homology domain, facilitating the PDPK1-dependent phosphorylation of T308-Akt (44) (Figure 4-2A). To establish the Xenopus egg extract as a plausible model to study PI3K/Akt activation, we first incubated pIRS peptide in extract and immunoblotted for p-T308-Akt. Extract was supplemented with PIP2 to ensure that it was not rate limiting in the assay. Interestingly, only incubation of long-chain PIP2 (PIP2-16) with the pIRS peptide resulted in T308-Akt phosphorylation (Figure 4-2B). The activation of PI3K/Akt by pIRS peptide was inhibited by the documented PI3K inhibitors, wortmannin (Wort) and LY294002 (LY) (87 and 88, respectively), as evaluated by p-T308-Akt immunoblot (Figure 4-2C and

Figure 4-2D, respectively). The data here identifies the Xenopus extract as a novel tool to study the canonical activation of PI3K/Akt and thus allowed us to next examine the activation of PI3K/Akt in our established model of aberrant glucose signaling. 

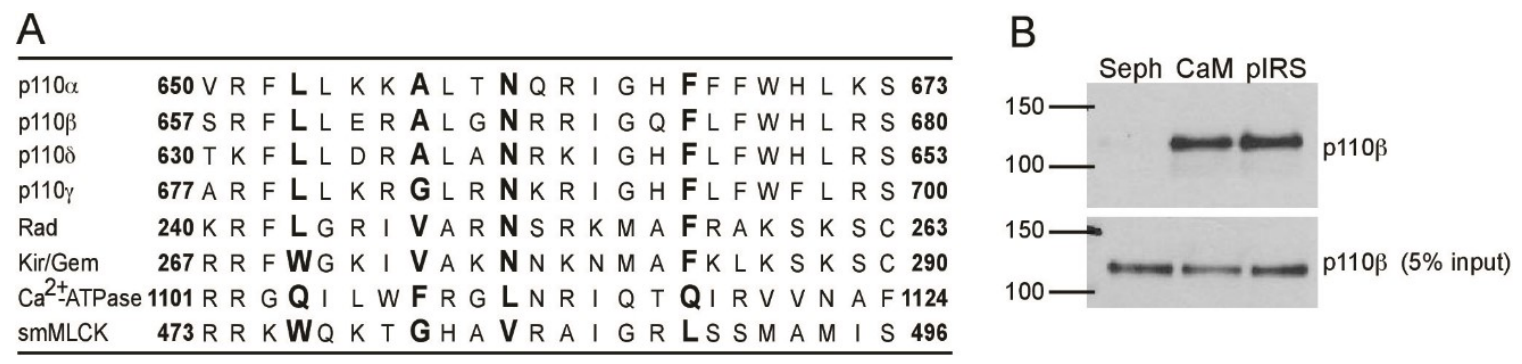

\section{Figure 4-1. Calmodulin directly binds PI3K.}

A, Putative calmodulin-binding sequences found in class I PI3K catalytic subunit isoforms are aligned with known CBDs of Kir/Gem, Rad, calcium ATPase and smooth muscle myosin light chain kinase (smMLCK). Conserved, hydrophobic residues are highlighted in bold (85). B, CaM-Sepharose, pIRS-Sepharose or Sepharose alone were incubated with $14 \mathrm{nM}$ recombinant human p110 $3 / \mathrm{p} 85 \alpha$ in $50 \mathrm{mM}$ HEPES buffer. Beads and $5 \%$ input of each sample were immunoblotted for $\mathrm{p} 110 \beta . \mathrm{n}=3$. 

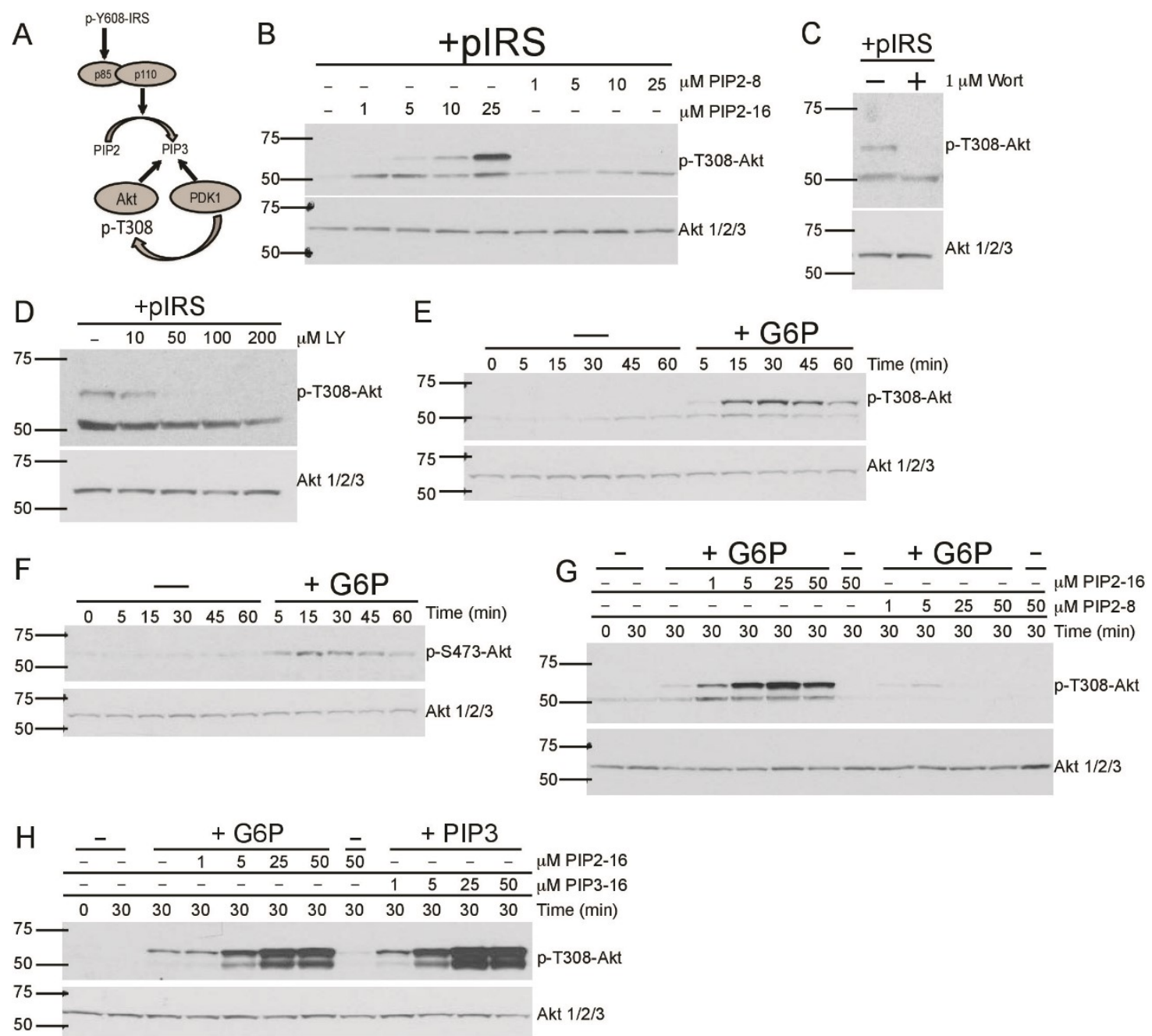

Figure 4-2. Aberrant glucose signaling activates Akt.

A, Canonical activation of PI3K/Akt by p-T608-IRS1. B, Extract was incubated with 1 $\mu \mathrm{g} / \mu \mathrm{L}$ pIRS peptide in the absence and presence of indicated concentrations of longchain PIP2 (PIP2-16) or short-chain PIP2 (PIP2-8). Samples were taken at 30 minutes and immunoblotted for p-T308-Akt. $\mathrm{n}=3$. $\mathbf{C}, 1$ microgram $(\mu \mathrm{g}) / \mu \mathrm{L}$ pIRS peptide $+20 \mathrm{uM}$ long-chain PIP2 was incubated in extract in the absence and presence of $1 \mu \mathrm{M}$ wortmannin. Samples were taken at 30 minutes and immunoblotted for $\mathrm{p}$-T308-Akt. $\mathrm{n}=3$. D, Experiment was performed as in C with indicated concentrations of LY294002. $n=3$. E, Extract $+1 \mu \mathrm{M}$ PIP2-16 was incubated in the absence and presence of $20 \mathrm{mM} \mathrm{G6P}$. Samples were taken at indicated times and immunoblotted for $\mathrm{p}-\mathrm{T} 308-\mathrm{Akt} . \mathrm{n}>3$. F, Experiment was performed as in E and samples immunoblotted for p-S473-Akt. n=3. G, Extract was incubated in the presence of $20 \mathrm{mM} \mathrm{G6P}$ and indicated concentrations of long or short-chain PIP2. Control samples were extract alone, $+50 \mu \mathrm{M}$ long or $50 \mu \mathrm{M}$ short-chain PIP2. Samples were taken at indicated times and immunoblotted for p-T308Akt. $n=3$. H, Extract was incubated alone, in the presence of $20 \mathrm{mM} \mathrm{G6P}+$ indicated concentrations of long-chain PIP2, and in the presence of indicated concentrations of long-chain PIP3. Samples were taken at indicated times and immunoblotted for $\mathrm{p}$-Akt T308. $n=3$. All n's are of independent experiments. 


\section{Aberrant glucose signaling activates Akt}

Our previous work delineates a model of aberrant glucose signaling where addition of G6P results in an increase in cytosolic acetyl CoA levels and subsequently CoA levels via a yet undescribed metabolic pathway. CoA binds directly to CaMKII within the CaM binding domain, activating CaMKII (67). Given our results confirming PI3K as a CaM binding protein and establishing a working model of PI3K-dependent Akt activation in Xenopus egg extract, we next evaluated PI3K activation in the context of our established model of aberrant glucose signaling.

Using phosphorylation of T308-Akt as a reporter of PI3K activity, extract was incubated with G6P and immunoblotted for p-T308- and p-S473-Akt. G6P-induced sustained phosphorylation of both T308- and S473-Akt (Figure 4-2E and Figure 4-2F). While G6P addition alone was sufficient to activate Akt, titration of the long chain, and not short chain PIP2, resulted in a dose-dependent increase in T308-Akt phosphorylation (Figure 4-2G), similar to pIRS peptide addition (Figure 4-2B). Furthermore, titration of another Akt activator, long-chain PIP3 resulted in a strong phosphorylation of T308-Akt (Figure 4-2H) similar to G6P (Figure 4-2G) whereas short-chain PIP3 did not (data not shown). While the activation of PI3K/Akt has been extensively studied under conventional growth factor stimulation, this is the first evidence that aberrant glucose metabolism, represented by G6P addition, is capable of activating PI3K and in turn Akt. Taken together, the data here establishes the Xenopus egg extract as a novel tool to study $\mathrm{PI} 3 \mathrm{~K} / \mathrm{Akt}$ activation both in the context of canonical phospho-tyrosine peptide stimulation as well as our novel model of G6P-mediated aberrant glucose signaling.

\section{Aberrant glucose metabolic activation of Akt is PI3K- and PDPK1-dependent}

To confirm that the metabolic activation of Akt by G6P was indeed occurring via a novel metabolite-mediated activation of PI3K, T308-Akt phosphorylation was analyzed in the presence of G6P and two different PI3K inhibitors. Indeed, both wortmannin and LY inhibited the G6P-mediated phosphorylation of T308-Akt (Figure 4-3A and Figure 4-3B). Next, we affinity depleted PI $3 \mathrm{~K}$ using two different methods. Extracts were incubated with either pIRS-Sepharose or CaM-Sepharose and serial depleted for PI3K. Figure 4-3C (left panel) and Figure 4-3D, demonstrate that both the pIRS peptide and CaM resins significantly depleted PI3K. Furthermore, the G6P-dependent metabolic activation of Akt was significantly abrogated in PI3K-depleted extract as compared to Sepharose-depleted control extract (Figure 4-3C, right panel, and Figure 4-3E). These results confirm that the G6P-mediated activation of Akt observed in extract is occurring via PI3K activation and thus supports our finding of a novel metabolic activation of PI3K/Akt.

While phosphorylation of T308-Akt is indeed an accepted indicator of PI3K activity, it is nonetheless an indirect reporter. To look at endogenous PI3K activity directly, we performed a PI3K TLC kinase assay in Xenopus extract, looking at 
Figure 4-3. Aberrant glucose metabolic activation of Akt is PI3K and PDPK1dependent.

A, Extract $+1 \mu \mathrm{M}$ PIP2-16 was incubated in the absence and presence of $20 \mathrm{mM}$ G6P and indicated concentrations of wortmannin. Samples were taken at indicated times and immunoblotted for p-T308-Akt. n>3. B, Experiment was performed as in A, with indicated concentrations of LY294002. $n=3$. C, Extract was affinity depleted using pIRSSepharose or Sepharose. Depleted extracts were then incubated with pIRS-Sepharose for $30 \mathrm{~min}$ at RT. Beads were immunoblotted for $\mathrm{p} 110 \alpha$ and $\mathrm{p} 85 \alpha$ (left panel). Depleted extracts were incubated with $1 \mu \mathrm{M}$ PIP2-16 in the absence and presence of $20 \mathrm{mM}$ G6P and samples were taken at indicated times and immunoblotted for p-T308-Akt (right panel). $\mathrm{n}=3$. D, CaM-Sepharose or Sepharose depleted extracts were incubated with pIRS-Sepharose for $30 \mathrm{~min}$ at RT and beads were immunoblotted for $\mathrm{p} 110 \alpha$ and $\mathrm{p} 85 \alpha$. $\mathrm{n}=3$. E, CaM-Sepharose or Sepharose control depleted extracts $+1 \mu \mathrm{M}$ PIP2-16 were incubated in the absence and presence of $20 \mathrm{mM}$ G6P. Samples were taken at indicated time points and immunoblotted for p-T308- and p-S473-Akt. $n=3$. F, Extract was incubated with $5 \mathrm{mM} \mathrm{MgCl} 2,100 \mu \mathrm{M}$ ATP, $70 \mathrm{nCi} / \mu \mathrm{L}\left[\gamma^{32}{ }^{32} \mathrm{P}\right] \mathrm{ATP}$ with $100 \mathrm{ng} / \mu \mathrm{L}$ PIP2 alone or $+20 \mathrm{mM} \mathrm{G6P}+/$ - wortmannin or LY. All reactions were run for $20 \mathrm{~min}$ at RT and resolved by TLC in chloroform:methanol:water:acetic acid $(10: 10: 3: 1, v / v) . n>3$. G, $20 \mathrm{mM}$ G6P + $1 \mu \mathrm{M}$ PIP2-16, $2 \mu \mathrm{M}$ PIP3-16, or $1 \mu \mathrm{g} / \mu \mathrm{L}$ pIRS $+20 \mu \mathrm{M}$ PIP2-16 were each incubated in extract in the presence of indicated concentrations of GSK2334470 (GSK). Samples were incubated for $30 \mathrm{~min}$ at RT and immunoblotted for p-T308-Akt. Negative control extract contained $20 \mu \mathrm{M}$ PIP2-16. n=3. All n's are of independent experiments. 

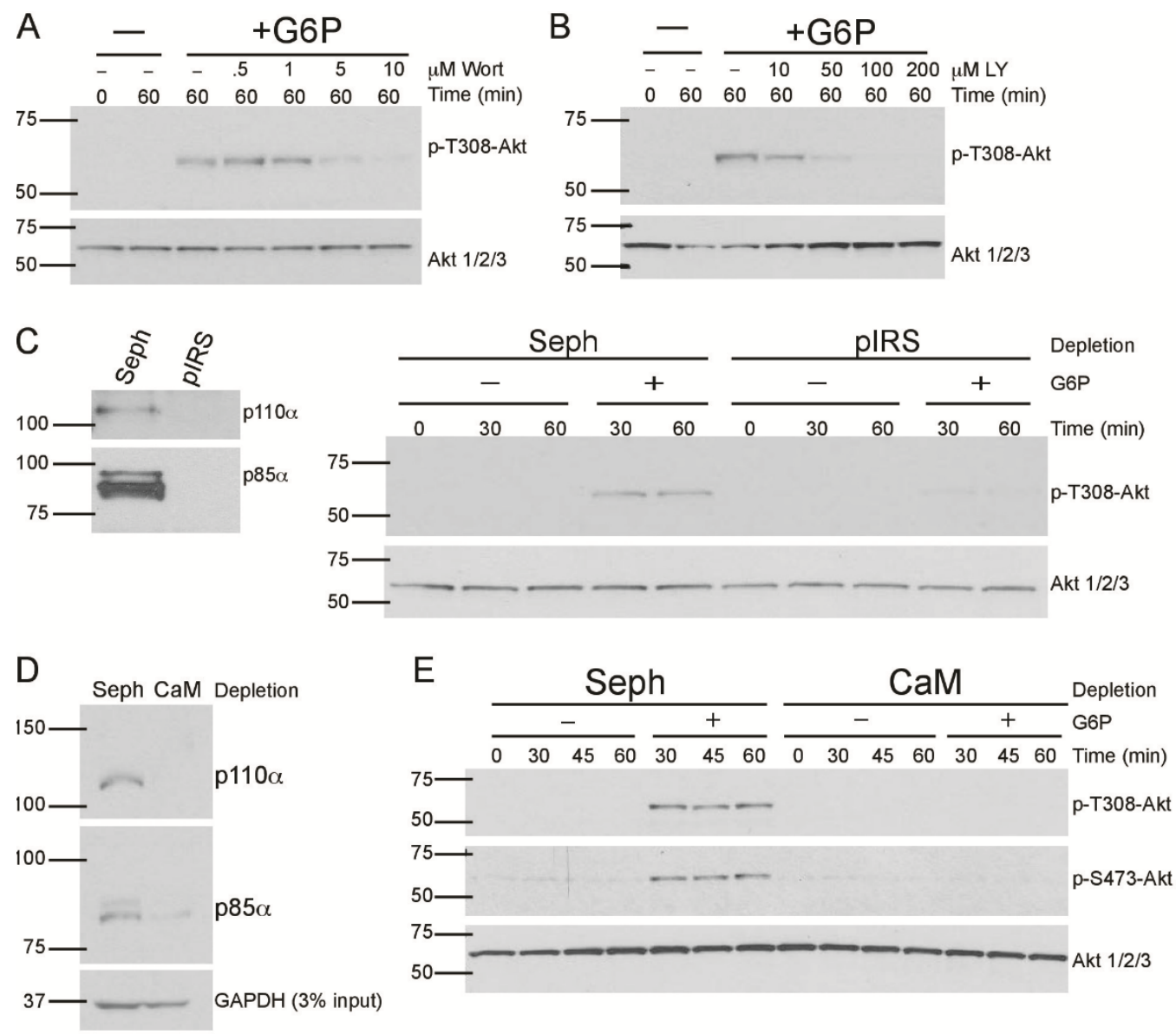

F

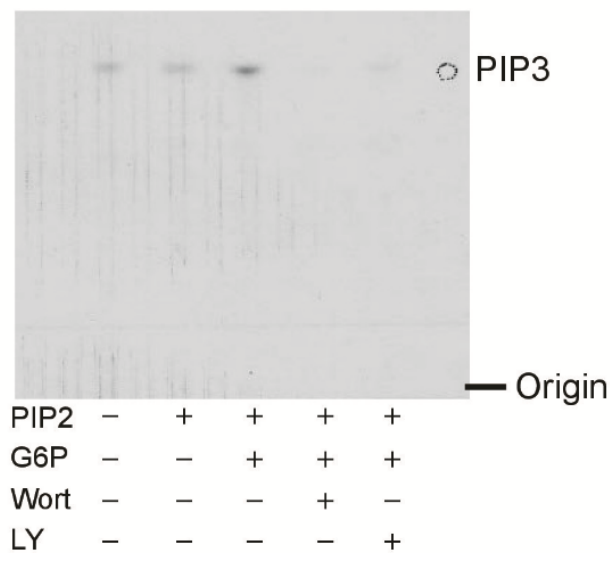

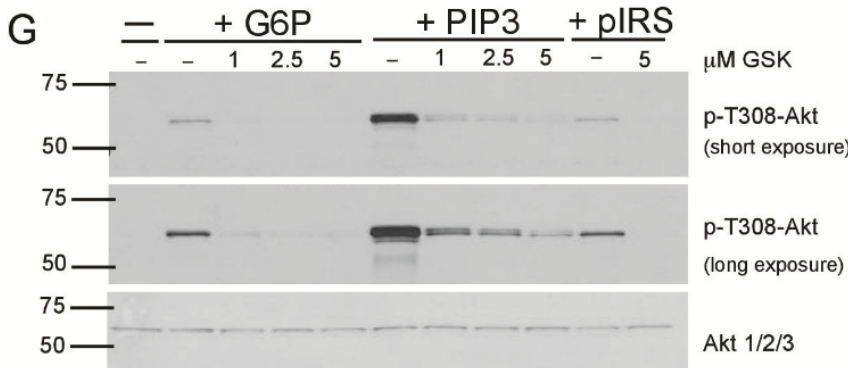


phosphorylation of the class IA PI3K substrate PIP2 18:0/20:4. Extract was incubated with $\left[\gamma-{ }^{32} \mathrm{P}\right] \mathrm{ATP}$ and $100 \mathrm{ng} / \mu \mathrm{L}$ PIP2 18:0/20:4 in the absence and presence of G6P with and without wortmannin or LY. Reactions were run for 20 minutes at room temperature and resolved by TLC in chloroform:methanol:water:acetic acid (10:10:3:1, v/v). G6P addition to the extract resulted in PI3K phosphorylation of PIP2 as measured by an increase in PIP3 production (Figure 4-3F). In addition, both wortmannin and LY inhibited the G6P-dependent PI3K phosphorylation of PIP2 (Figure 4-3F). We next tested if our novel metabolic activation of PI3K/Akt is PDPK1-dependent as is the case in its canonical activation. The PDPK1 inhibitor GSK2334470 (GSK) effectively blocked PI3K-dependent Akt activation by G6P as well as by PIP3 and pIRS peptide controls (Figure 4-3G). The results indicate PDPK1-dependent phosphorylation of T308-Akt is conserved in our novel metabolic regulation of PI3K-dependent Akt activation.

Furthermore, both chemical or affinity reduction of PI3K inhibited PI3K/Akt activation by aberrant glucose metabolism. Finally, direct analysis of PI3K activity confirmed the metabolic activation of PI3K.

\section{CoA mediates a novel metabolic activation of PI3K/Akt}

Our previous work identified a G6P-pentose phosphate pathway-AcetylCoA-CoA metabolic cascade resulting in the metabolic activation of CaMKII (67). However, aberrant glucose signaling (as mimicked by G6P addition) may have direct or indirect effects resulting in PI3K/Akt activation. To determine whether our novel metabolic activation of PI3K/Akt occurs in a similar fashion, we treated extracts with a nonmetabolizable 2-deoxyglucose-6-phosphate (2D-G6P) and assayed PI3K activity by immunoblotting for p-T308-Akt. G6P induced phosphorylation of T308-Akt; however, addition of 2D-G6P had no effect (Figure 4-4A), indicating that G6P catabolism, mimicking aberrant glucose signaling, is responsible for the novel activation of PI3K/Akt.

We next tested the ability of CoA, the key metabolic signaling cofactor in our model of aberrant glucose signaling, to activate endogenous PI3K. CoA addition to the extract in the presence of long-chain PIP2 activated PI3K-dependent T308-Akt phosphorylation as well as S473-Akt phosphorylation (Figure 4-4B and Figure 4-4C, respectively). Additionally, the PI3K inhibitors, wortmannin and LY, abrogated the CoAmediated metabolic activation of Akt in the extract (Figure 4-4D and Figure 4-4E, respectively). This novel CoA-dependent, metabolic activation of PI3K/Akt was also inhibited by GSK, again indicating conservation of the role of PDPK1 in PI3K-dependent Akt activation (Figure 4-4F). These findings corroborate $\mathrm{CoA}$ as the key metabolic signaling factor in our model of aberrant glucose signaling, mediating the novel metabolic activation of PI3K, in turn activating downstream Akt in a PDPK1-dependent manner. 

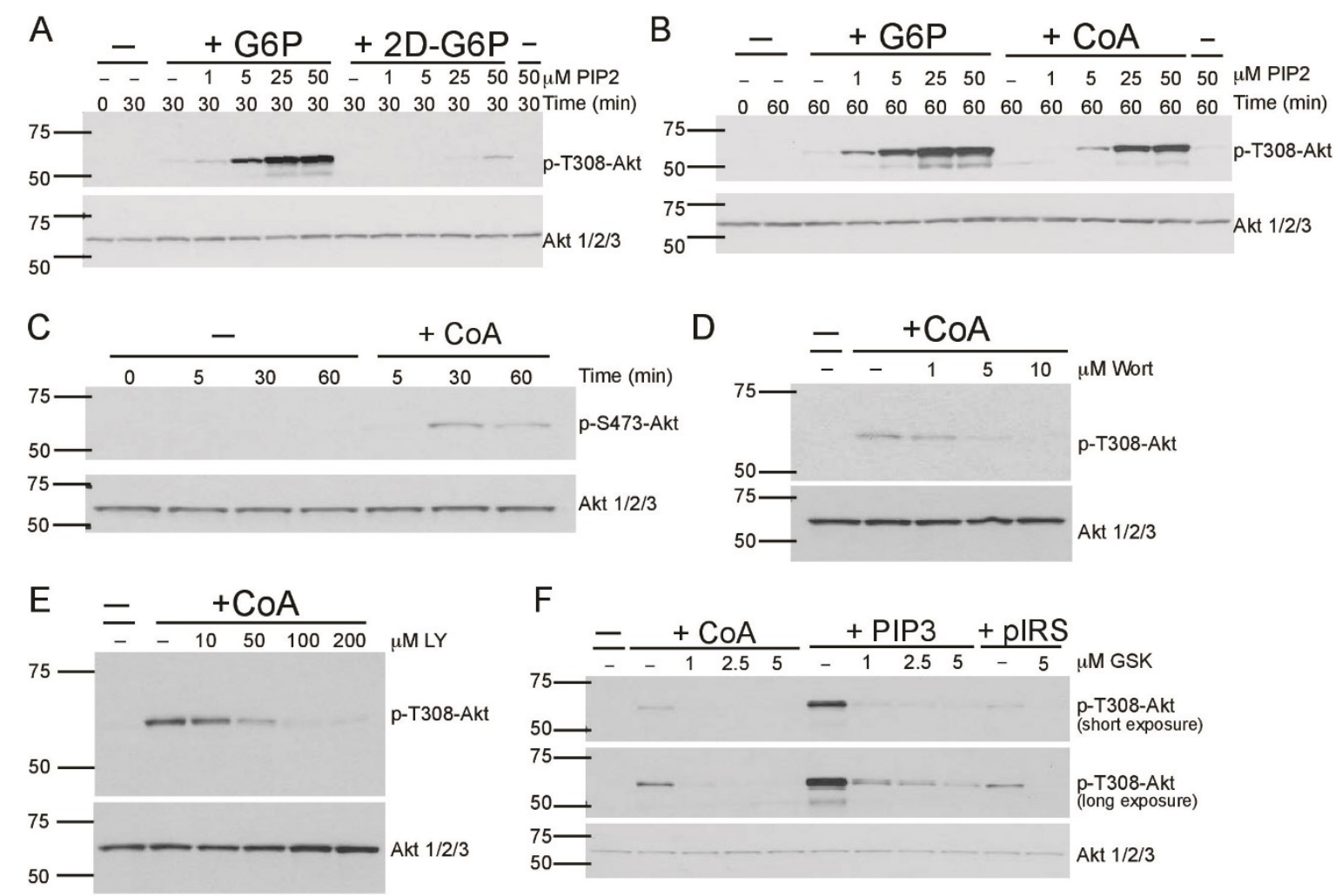

Figure 4-4. CoA mediates a novel metabolic activation of PI3K/Akt.

A, Extract was incubated in the absence or presence of $20 \mathrm{mM}$ G6P or $20 \mathrm{mM} 2$ deoxyglucose-6-phosphate (2D-G6P) and indicated concentrations of PIP2-16. Samples were taken at indicated times and immunoblotted for $\mathrm{p}-\mathrm{T} 308-\mathrm{Akt}$. $\mathrm{n}=3$. B, Extract was incubated with $20 \mathrm{mM} \mathrm{G6P}$ or $10 \mathrm{mM} \mathrm{CoA}$ and indicated concentrations of PIP2-16. Samples were taken at indicated time points and immunoblotted for $\mathrm{p}-\mathrm{T} 308$-Akt. $\mathrm{n}=3$. C, Extract $+10 \mu \mathrm{M}$ PIP2-16 was incubated in the presence or absence of $10 \mathrm{mM}$ CoA.

Samples were taken at indicated time points and immunoblotted for $\mathrm{p}-\mathrm{S} 473-\mathrm{Akt}$. $\mathrm{n}=3$. D, Extract $+10 \mu \mathrm{M}$ PIP2-16 was incubated in the absence and presence of $10 \mathrm{mM} \mathrm{CoA}$ and indicated concentrations of wortmannin. Samples were incubated at RT for $30 \mathrm{~min}$ and immunoblotted for $\mathrm{p}-\mathrm{T} 308$-Akt. $\mathrm{n}=3$. E, Experiment was performed as in $\mathrm{D}$, with indicated concentrations of LY. n=3. F, $10 \mathrm{mM} \mathrm{CoA}+10 \mu \mathrm{M}$ PIP2-16, $2 \mu \mathrm{M}$ PIP3-16, or $1 \mu \mathrm{g} / \mu \mathrm{L}$ pIRS $+20 \mu \mathrm{M}$ PIP2-16 were each incubated in extract in the presence of indicated concentrations of GSK2334470 (GSK). Samples were incubated for $30 \mathrm{~min}$ at RT and immunoblotted for p-T308-Akt. Negative control extract contained $20 \mu \mathrm{M}$ PIP216. $n=3$. All n's are of independent experiments. 


\section{CoA activation of Akt is PI3K-dependent}

The results presented thus far identify a novel CoA-mediated metabolic activation of PI3K/Akt. Given this and our previous work demonstrating that CoA binds the CaMBD and activates CaMKII, we hypothesized that CoA similarly binds and activates PI3K. First, CoA was immobilized on Affi-Gel via the primary amine of the adenine ring. Then, CoA-Affi-Gel was incubated in HeLa cell extracts, washed and resolved by SDSPAGE. CoA successfully affinity precipitated endogenous PI3K (Figure 4-5A). To further provide evidence that CoA binds PI3K, we tested whether serial affinity precipitations would efficiently deplete PI3K in Xenopus extract. To assay PI3K protein levels, depleted extracts were incubated with pIRS-Sepharose. Isolated complexes were resolved by SDS-PAGE and immunoblotted for endogenous PI3K. PI3K was significantly depleted in CoA-Affi-Gel depleted extracts (Figure 4-5B). Moreover, metabolic activation of Akt, as indicated by T308- and S473-Akt phosphorylation, was inhibited in PI3K-depleted extracts (Figure 4-5C). These results demonstrate the ability of CoA to bind endogenous PI3K and corroborate our novel mechanism whereby aberrant glucose signaling, mediated by CoA, activates Akt in a PI3K-dependent manner.

\section{Coenzyme A directly binds and activates class I PI3K}

Given that CoA binds endogenous PI3K, we next determined whether CoA directly interacts with PI3K. Indeed, when CoA-Affi-Gel was incubated in buffer with recombinant $\mathrm{p} 110 \beta / \mathrm{p} 85 \alpha$, washed and resolved by SDS-PAGE, CoA directly bound recombinant PI3K (Figure 4-5D). Since CoA directly bound to PI3K, we then evaluated the ability of CoA to directly activate PI3K. Recombinant $\mathrm{p} 110 \beta / \mathrm{p} 85 \alpha$ activity was analyzed in the absence and presence of free CoA or pIRS peptide in a direct TLC kinase assay using $24 \mathrm{ng} / \mu \mathrm{L}$ PIP2 18:0/20:4 as substrate with $\left[\gamma_{-}{ }^{32} \mathrm{P}\right] \mathrm{ATP}$. Reactions were incubated for $20 \mathrm{~min}$ at room temperature in $50 \mathrm{mM}$ HEPES buffer and resolved by TLC in $n$-propanol:water:acetic acid (64:33:2, v/v). Addition of CoA significantly increased PIP3 production by more than 3 -fold as compared to basal PI3K activity (Figure 4-5E). Addition of $p$ IRS peptide activated recombinant $\mathrm{p} 110 \beta / \mathrm{p} 85 \alpha$ by a two-fold increase (Figure 4-5E). Furthermore, a titration of CoA significantly increased PI3K activity at physiologically relevant concentrations found in mammalian cells starting from $1 \mathrm{mM}$ to $10 \mathrm{mM}$ (Figure 4-5F). Taken together, this data demonstrates that $\mathrm{CaM}$ is not required for the novel metabolic activation of PI3K, and CoA, the pivotal metabolic signaling molecule in our model of aberrant glucose metabolism, directly binds to and activates a representative class IA PI3K, p110 $\beta / \mathrm{p} 85 \alpha$. 
Figure 4-5. Coenzyme A directly binds and activates class I PI3K. A, CoA-Affi-Gel or Affi-Gel control beads were incubated in HeLa cell cytosol. Beads and $10 \%$ input of each sample was immunoblotted for $\mathrm{p} 110 \beta . \mathrm{n}=3$. B, CoA-Affi-Gel or Affi-Gel depleted extracts were incubated with pIRS-Sepharose for $30 \mathrm{~min}$ at RT and beads were immunoblotted for $\mathrm{p} 110 \alpha$ and $\mathrm{p} 85 \alpha . \mathrm{n}=3$. C, CoA-Affi-Gel or Affi-Gel control depleted extracts $+1 \mu \mathrm{M}$ PIP2-16 were incubated in the absence and presence of $20 \mathrm{mM}$ G6P. Samples were taken at indicated time points and immunoblotted for $\mathrm{p}-$ T308- and p-S473-Akt. n=3. D, CoA-Affi-Gel or Affi-Gel were incubated in $50 \mathrm{mM}$ HEPES buffer with $14 \mathrm{nM}$ recombinant $\mathrm{p} 110 \beta / \mathrm{p} 85 \alpha$. Beads and 5\% input of each sample were immunoblotted for $\mathrm{p} 110 \beta . \mathrm{n}=3$. E, A direct TLC kinase assay was performed in the absence and presence of $14 \mathrm{nM}$ recombinant $\mathrm{p} 110 \beta / \mathrm{p} 85 \alpha$ alone, $+10 \mathrm{mM} \mathrm{CoA}$, or +27.2 $\mu \mathrm{g} / \mu \mathrm{L}$ pIRS peptide; all in the presence of $24 \mathrm{ng} / \mu \mathrm{L}$ PIP2 18:0/20:4, $5 \mathrm{mM} \mathrm{MgCl} 2,100$ $\mu \mathrm{M}$ ATP, and $70 \mathrm{nCi} / \mu \mathrm{L}\left[\gamma^{32} \mathrm{P}\right] \mathrm{ATP}$. Reactions were incubated for $20 \mathrm{~min}$ at RT in 50 mM HEPES buffer and resolved by TLC in $n$-propanol:water:acetic acid $(64: 33: 2, \mathrm{v} / \mathrm{v})$. PIP3 18:0/20:4 was run alongside, identified by iodine vapor exposure and its location marked on the TLC silica plate prior to autoradiography. PIP3 spot intensities for CoA and pIRS treatments were quantified, relative to PI3K alone, using imageJ software (72). Statistical analysis for CoA and pIRS was done using paired t-test, each relative to PI3K alone (CoA, $\mathrm{p}=.0003$; $\mathrm{pIRS}, \mathrm{p}=.0003)$. Standard deviation error bars are shown. $\mathrm{n}=5$. $\mathbf{F}$, Direct TLC kinase assay was repeated in the absence and presence of $14 \mathrm{nM}$ recombinant $\mathrm{p} 110 \beta / \mathrm{p} 85 \alpha$ alone, $+.05, .5,1,5$, or $10 \mathrm{mM} \mathrm{CoA}$. PIP3 standard was run alongside samples as shown. Quantification and statistical analysis was done as in $\mathrm{C}(\mathrm{p}<.0001$ for 1 $\mathrm{mM}$ CoA, $\mathrm{p}=.0013$ for $5 \mathrm{mM}$ CoA, $\mathrm{p}=.0105$ for $10 \mathrm{mM} \mathrm{CoA}$ ). Standard deviation error bars are shown. $n=3$. All n's are of independent experiments. 

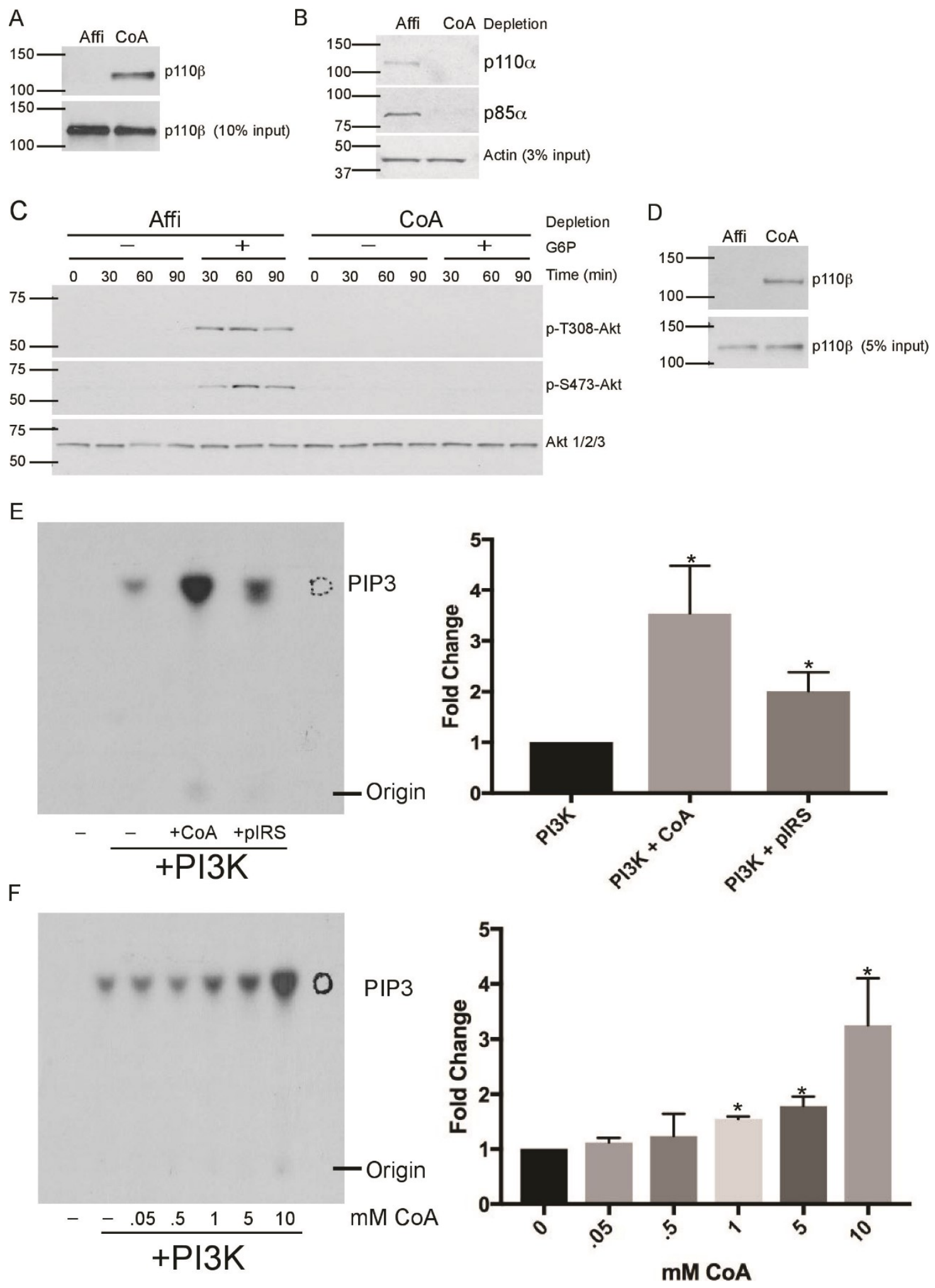


\section{CHAPTER 5. DISCUSSION}

We previously characterized a novel G6P-NADPH-acetylCoA-CoA metabolic cascade resulting in the activation of CaMKII (66-69). CoA, the key metabolic signaling cofactor in our model of aberrant glucose signaling, directly binds and activates CaMKII (67). We postulated that CoA similarly interacts and metabolically regulates other CaMdependent enzymes. In the current studies, we demonstrate that numerous CaM-binding proteins bind CoA and identify $\mathrm{PI} 3 \mathrm{~K}$ as a specific, direct interactor of $\mathrm{CoA}$, facilitating the metabolic activation of the PI3K/Akt pathway in a PDPK1-dependent manner. These findings uncover a novel mechanism of PI3K activation by aberrant glucose signaling and identify a potential process of constitutive activation of the PI3K pathway in tumor cells.

$\mathrm{CaM}$ binds its client proteins in either a calcium dependent or independent manner. $\mathrm{Ca}^{2+}$-dependent calmodulin binding proteins can be further classified into three groups (1-10, 1-14, and 1-16) based on the spacing of bulky hydrophobic and basic amino acid residues within the 20 amino acid CaMBD (78). Our previous work demonstrated direct $\mathrm{CoA}$ binding to the CaMBD of CaMKII, a 1-10 calmodulin binding protein. As shown in Figure 4-1A, the putative CaMBD mapped within the p1 10 catalytic subunit of PI3K contains hydrophobic residues conserved among the four class I $\mathrm{PI} 3 \mathrm{~K}$ isoforms and the 1-14 calmodulin binding proteins. The ability of CoA to directly bind and activate PI3K therefore extends our model of aberrant metabolic regulation to potentially include other 1-14 and 1-10 CaM-dependent enzymes. Indeed, our two-step tandem purification shown here demonstrates the existence of multiple CaM-binding proteins that also bind CoA. Furthermore, when CoA was immobilized on Affi-Gel matrix and incubated in Xenopus extract, $\mathrm{Ca}^{2+} /$ calmodulin-dependent kinase IV and calcineurin were successfully precipitated (Figure 5-1) demonstrating that CoA binding CaMBD may be a novel locus of metabolic control for a subclass of calmodulin binding proteins. Given the conservation of hydrophobic residues in the primary sequences of $\mathrm{Ca}^{2+} /$ calmodulin binding domains (53), these findings suggest a novel function for calmodulin binding proteins regulated by metabolism through CoA binding.

Our current and previous findings support a new concept of metabolites/co-factors acting as important second messengers in cellular signaling. Increased levels of cytosolic acetyl-CoA have been detected in cancer. This emerging area of cancer biology is attracting attention as acetyl-CoA levels regulate general protein acetylation and specifically histone acetylation, in turn regulating gene transcription. Acetyl-CoA metabolism may therefore be a node of control for cancer epigenetics. Our finding that free CoA, generated from the breakdown of acetyl-CoA, regulates oocyte survival contributes to the concept of metabolites/co-factors directly regulating enzyme function. Furthermore, we have extended this model here to show that CoA binds multiple CaMbinding proteins and metabolically activates PI3K.

While CoA is sufficient to directly bind and activate PI3K in vitro, acetyl-CoA or another small-chain or long-chain acyl-CoA may be the relevant mediator of the 
A

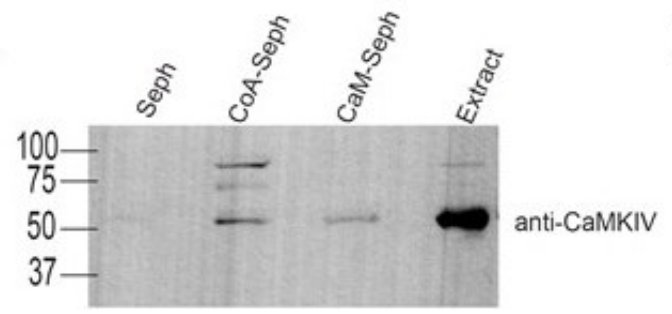

B

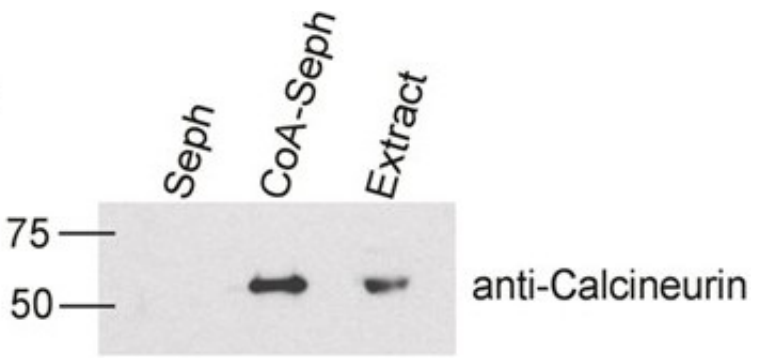

Figure 5-1. CoA binds endogenous CaMKIV and Calcineurin.

A, Xenopus extract was incubated with CoA-Sepharose, CaM-Sepharose or Sepharose for 30 minutes at RT. Beads were isolated, washed and immunoblotted for CaMKIV. $\mathrm{n}=2$. B, Experiment was performed as in A with Sepharose or CoA-Sepharose and immunoblotted for calcineurin. $\mathrm{n}=2$. 
metabolic activation of PI3K/Akt in vivo. Long-chain acyl CoA derivatives have been shown to specifically activate the CaM-binding ryanodine receptor (89). Palmitoyl-CoAactivated ryanodine channel was shown to be sensitive to calcium in the presence of inhibitory, millimolar concentrations of $\mathrm{Mg}^{2+}$ (89). Cytosolic levels of acetyl CoA are known to increase in conditions of anabolic states, cellular proliferation and differentiation (6). Acetyl-CoA, as a signaling metabolite, mediates the acetylation of proteins most notably histones, relaxing chromatin structure and ultimately inducing gene expression that promotes differentiation or proliferation (6). This allows the cell to coordinate such metabolically demanding processes with its metabolic state.

The growth factor-dependent metabolic state of the cell may be regulated by the G6P-acetylCoA-CoA mediated activation of PI3K/Akt. The canonical activation of PI3K/Akt by growth factors results in Akt-mediated translocation of glucose transporters to the cell membrane, activation of hexokinase and phosphofructokinase-1 as well as the mTORC1-mediated upregulation of glycolytic enzymes and G6PD via HIF1 and Myc induction (53-56). This increased glucose metabolism is necessary to support differentiation and proliferation stimulated by growth factor signaling. The novel metabolic activation of PI3K/Akt described here may represent a feed-forward signal under physiological conditions that coordinates increased glucose metabolism with such bioenergetically demanding processes stimulated by growth factor signaling. However, under pathological conditions such as aberrant metabolism in cancer, this novel metabolic activation of PI3K/Akt may represent a new mechanism of constitutive activation of the pathway in tumor cells.

Constitutive activation of PI3K/Akt occurs in a large, diverse number of human cancers primarily via mutation in the catalytic subunit $\mathrm{p} 110 \alpha$ of class IA PI3K (90). About $80 \%$ of the mutations map to three hot spots substitutions, E542K and E545K in the helical domain and H1047R within the kinase domain (90). These mutations increase PI3K enzymatic activity, constitutively activate Akt, induce growth factor- and anchorage-independent growth in cell culture, and cause tumors in vivo (91-96). Biochemical and structural studies suggest that the E542K and E545K mutations relieve an inhibitory interaction between the N-terminal SH2 domain of the regulatory $\mathrm{p} 85$ subunit and the helical domain of p110 $\alpha$, resulting in constitutive kinase activity (97-99). Interestingly, the putative calmodulin binding domain mapped within the $\mathrm{p} 110 \alpha$ catalytic subunit lies at the $\mathrm{C}$-terminus of the helical domain. CoA direct binding to this CaMBD may result in a conformational change that likewise relieves the allosteric inhibition of the p85 regulatory subunit on the p110 catalytic subunit (Figure 5-2). In this fashion, aberrant glucose signaling generating CoA may act as an independent activator of PI3K or in the presence of these genetic mutations, direct CoA binding may synergistically augment PI3K activity. In this manner, as one of the defined hallmarks of cancer cells (3), aberrant metabolism generating increased cytosolic acetyl-CoA and CoA levels may coordinate a novel mechanism of constitutive activation of PI3K/Akt via direct CoA interaction.

Studying altered metabolic regulation in mammalian cells is cumbersome given the impermeability of most intermediate metabolites. The Xenopus oocyte system has 


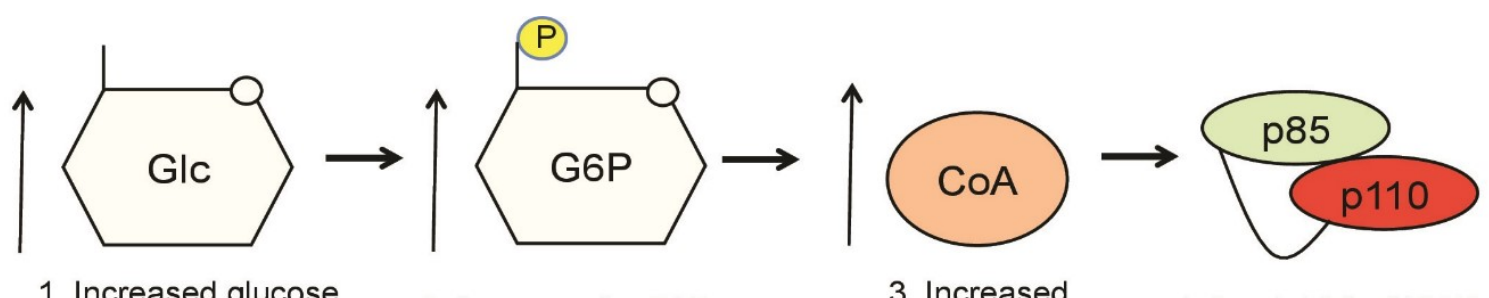

1. Increased glucose metabolism

2. Increase in G6P

3. Increased cytosolic CoA levels

4. Autoinhibited PI3K

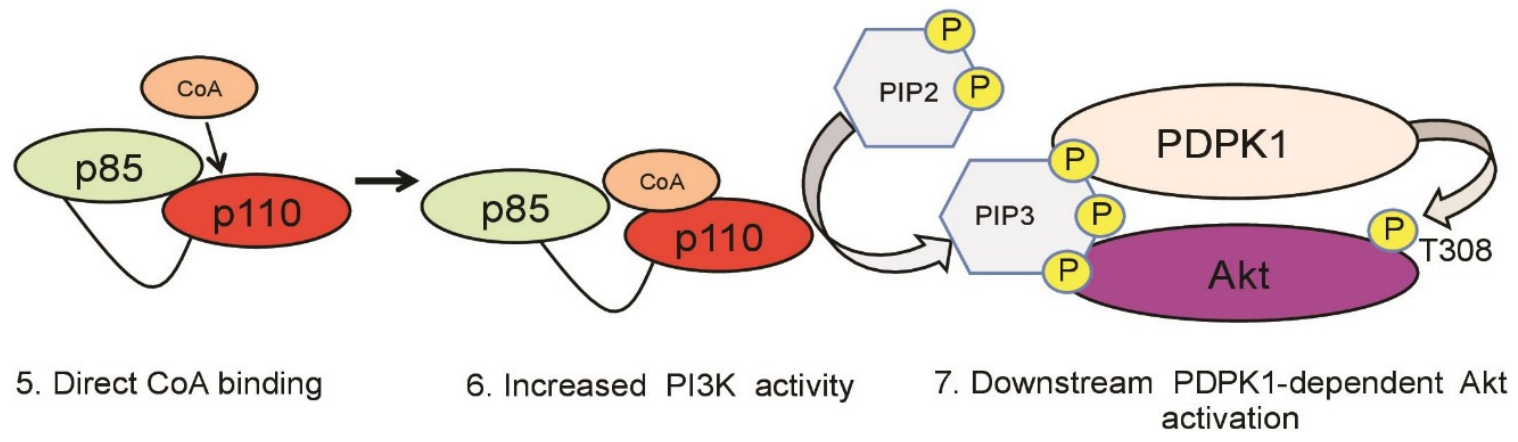

Figure 5-2. CoA directly binds and activates PI3K, mediating the novel metabolic activation of PI3K/Akt.

Schematic of the novel metabolic activation of PI3K. Increased glucose metabolism via G6P fluxing through the PPP leads to increased cytosolic CoA levels. CoA directly binds to $\mathrm{PI} 3 \mathrm{~K}$, potentially relieving the allosteric inhibition of the p 85 subunit on the p1 10 catalytic subunit. Active PI3K phosphorylates PIP2 to PIP3 which recruits PDPK1 and Akt, resulting in Akt phosphorylation and activation. 
been shown by our group and suggested by others to be a more biochemically tractable model system providing insights into tumor cell metabolism $(59,65)$. Here, using the Xenopus oocyte model system allowed us to discover the existence of multiple CaMbinding proteins that bind CoA as well as delineate a novel mechanism of PI3K/Akt activation by altered glucose signaling. A better understanding of the molecular mechanisms underlying this link could provide a viable therapeutic target applicable to many human cancers. 


\section{LIST OF REFERENCES}

1. Courtnay, R., Ngo, D. C., Malik, N., Ververis, K., Tortorella, S. M., and Karagiannis, T. C. (2015) Cancer metabolism and the Warburg effect: the role of HIF-1 and PI3K. Mol Biol Rep 42, 841-851

2. Hanahan, D., and Weinberg, R. A. (2000) The hallmarks of cancer. Cell 100, 5770

3. Hanahan, D., and Weinberg, R. A. (2011) Hallmarks of cancer: the next generation. Cell 144, 646-674

4. Vander Heiden, M. G., Cantley, L. C., and Thompson, C. B. (2009) Understanding the Warburg effect: the metabolic requirements of cell proliferation. Science 324, 1029-1033

5. Jiang, P., Du, W., and Wu, M. (2014) Regulation of the pentose phosphate pathway in cancer. Protein Cell 5, 592-602

6. Chandel, N. S. (2015) Navigating Metabolism, Cold Spring Harbor Laboratory Press, New York

7. Phan, L. M., Yeung, S. C., and Lee, M. H. (2014) Cancer metabolic reprogramming: importance, main features, and potentials for precise targeted anti-cancer therapies. Cancer Biol Med 11, 1-19

8. Warburg, O., Wind, F., and Negelein, E. (1927) The Metabolism of Tumors in the Body. J Gen Physiol 8, 519-530

9. Warburg, O. (1956) On respiratory impairment in cancer cells. Science 124, 269270

10. Warburg, O. (1956) On the origin of cancer cells. Science 123, 309-314

11. Deberardinis, R. J., Sayed, N., Ditsworth, D., and Thompson, C. B. (2008) Brick by brick: metabolism and tumor cell growth. Curr Opin Genet Dev 18, 54-61

12. DeBerardinis, R. J., and Cheng, T. (2010) Q's next: the diverse functions of glutamine in metabolism, cell biology and cancer. Oncogene 29, 313-324

13. Hsu, P. P., and Sabatini, D. M. (2008) Cancer cell metabolism: Warburg and beyond. Cell 134, 703-707

14. Jones, R. G., and Thompson, C. B. (2009) Tumor suppressors and cell metabolism: a recipe for cancer growth. Genes Dev 23, 537-548

15. Zheng, J. (2012) Energy metabolism of cancer: Glycolysis versus oxidative phosphorylation (Review). Oncol Lett 4, 1151-1157

16. Yeung, S. J., Pan, J., and Lee, M. H. (2008) Roles of p53, MYC and HIF-1 in regulating glycolysis - the seventh hallmark of cancer. Cell Mol Life Sci 65, 3981-3999

17. DeBerardinis, R. J., Lum, J. J., Hatzivassiliou, G., and Thompson, C. B. (2008) The biology of cancer: metabolic reprogramming fuels cell growth and proliferation. Cell Metab 7, 11-20

18. Dang, C. V. (2007) The interplay between MYC and HIF in the Warburg effect. Ernst Schering Found Symp Proc, 35-53

19. Dang, C. V., Lewis, B. C., Dolde, C., Dang, G., and Shim, H. (1997) Oncogenes in tumor metabolism, tumorigenesis, and apoptosis. J Bioenerg Biomembr 29, 345-354 
20. Denko, N. C. (2008) Hypoxia, HIF1 and glucose metabolism in the solid tumour. Nat Rev Cancer 8, 705-713

21. Wise, D. R., DeBerardinis, R. J., Mancuso, A., Sayed, N., Zhang, X. Y., Pfeiffer, H. K., Nissim, I., Daikhin, E., Yudkoff, M., McMahon, S. B., and Thompson, C. B. (2008) Myc regulates a transcriptional program that stimulates mitochondrial glutaminolysis and leads to glutamine addiction. Proc Natl Acad Sci U S A 105, $18782-18787$

22. Wang, P. Y., Zhuang, J., and Hwang, P. M. (2012) p53: exercise capacity and metabolism. Curr Opin Oncol 24, 76-82

23. Bensaad, K., Tsuruta, A., Selak, M. A., Vidal, M. N., Nakano, K., Bartrons, R., Gottlieb, E., and Vousden, K. H. (2006) TIGAR, a p53-inducible regulator of glycolysis and apoptosis. Cell 126, 107-120

24. Vahsen, N., Cande, C., Briere, J. J., Benit, P., Joza, N., Larochette, N., Mastroberardino, P. G., Pequignot, M. O., Casares, N., Lazar, V., Feraud, O., Debili, N., Wissing, S., Engelhardt, S., Madeo, F., Piacentini, M., Penninger, J. M., Schagger, H., Rustin, P., and Kroemer, G. (2004) AIF deficiency compromises oxidative phosphorylation. EMBO J 23, 4679-4689

25. Schwartzenberg-Bar-Yoseph, F., Armoni, M., and Karnieli, E. (2004) The tumor suppressor p53 down-regulates glucose transporters GLUT1 and GLUT4 gene expression. Cancer Res 64, 2627-2633

26. Kawauchi, K., Araki, K., Tobiume, K., and Tanaka, N. (2008) p53 regulates glucose metabolism through an IKK-NF-kappaB pathway and inhibits cell transformation. Nat Cell Biol 10, 611-618

27. Matoba, S., Kang, J. G., Patino, W. D., Wragg, A., Boehm, M., Gavrilova, O., Hurley, P. J., Bunz, F., and Hwang, P. M. (2006) p53 regulates mitochondrial respiration. Science 312, 1650-1653

28. Yang, J., Ahmed, A., Poon, E., Perusinghe, N., de Haven Brandon, A., Box, G., Valenti, M., Eccles, S., Rouschop, K., Wouters, B., and Ashcroft, M. (2009) Small-molecule activation of $\mathrm{p} 53$ blocks hypoxia-inducible factor 1 alpha and vascular endothelial growth factor expression in vivo and leads to tumor cell apoptosis in normoxia and hypoxia. Mol Cell Biol 29, 2243-2253

29. Koppenol, W. H., Bounds, P. L., and Dang, C. V. (2011) Otto Warburg's contributions to current concepts of cancer metabolism. Nat Rev Cancer 11, 325337

30. Dang, C. V. (1999) c-Myc target genes involved in cell growth, apoptosis, and metabolism. Mol Cell Biol 19, 1-11

31. Shi, M., Cui, J., Du, J., Wei, D., Jia, Z., Zhang, J., Zhu, Z., Gao, Y., and Xie, K. (2014) A novel KLF4/LDHA signaling pathway regulates aerobic glycolysis in and progression of pancreatic cancer. Clin Cancer Res 20, 4370-4380

32. Sheng, S. L., Liu, J. J., Dai, Y. H., Sun, X. G., Xiong, X. P., and Huang, G. (2012) Knockdown of lactate dehydrogenase A suppresses tumor growth and metastasis of human hepatocellular carcinoma. FEBS J 279, 3898-3910

33. Zhao, Y. H., Zhou, M., Liu, H., Ding, Y., Khong, H. T., Yu, D., Fodstad, O., and Tan, M. (2009) Upregulation of lactate dehydrogenase A by ErbB2 through heat shock factor 1 promotes breast cancer cell glycolysis and growth. Oncogene 28, 3689-3701 
34. Yao, M., Ishihara, H., Narita, M., Kudo, T., Matsuki, A., and Oyama, T. (1985) [Endocrine functions following epidural morphine administration. 7. Effects on on the thyroid function]. Masui 34, 25-29

35. Xian, Z. Y., Liu, J. M., Chen, Q. K., Chen, H. Z., Ye, C. J., Xue, J., Yang, H. Q., Li, J. L., Liu, X. F., and Kuang, S. J. (2015) Inhibition of LDHA suppresses tumor progression in prostate cancer. Tumour Biol 36, 8093-8100

36. Miao, P., Sheng, S., Sun, X., Liu, J., and Huang, G. (2013) Lactate dehydrogenase A in cancer: a promising target for diagnosis and therapy. IUBMB Life 65, 904910

37. Bonuccelli, G., Tsirigos, A., Whitaker-Menezes, D., Pavlides, S., Pestell, R. G., Chiavarina, B., Frank, P. G., Flomenberg, N., Howell, A., Martinez-Outschoorn, U. E., Sotgia, F., and Lisanti, M. P. (2010) Ketones and lactate "fuel" tumor growth and metastasis: Evidence that epithelial cancer cells use oxidative mitochondrial metabolism. Cell Cycle 9, 3506-3514

38. Martinez-Outschoorn, U. E., Prisco, M., Ertel, A., Tsirigos, A., Lin, Z., Pavlides, S., Wang, C., Flomenberg, N., Knudsen, E. S., Howell, A., Pestell, R. G., Sotgia, F., and Lisanti, M. P. (2011) Ketones and lactate increase cancer cell "stemness," driving recurrence, metastasis and poor clinical outcome in breast cancer: achieving personalized medicine via Metabolo-Genomics. Cell Cycle 10, 12711286

39. Berg JM, T. J., Stryer L. (2002) Amino Acids are Made from Intermediates of the Citric Acid Cycle and other Major Pathways. in Biochemistry, 5th Ed., W.H. Freeman, New York. Section 24.2

40. Liu, P., Cheng, H., Roberts, T. M., and Zhao, J. J. (2009) Targeting the phosphoinositide 3-kinase pathway in cancer. Nat Rev Drug Discov 8, 627-644

41. Engelman, J. A. (2009) Targeting PI3K signalling in cancer: opportunities, challenges and limitations. Nat Rev Cancer 9, 550-562

42. Engelman, J. A., Luo, J., and Cantley, L. C. (2006) The evolution of phosphatidylinositol 3-kinases as regulators of growth and metabolism. Nat Rev Genet 7, 606-619

43. Salmena, L., Carracedo, A., and Pandolfi, P. P. (2008) Tenets of PTEN tumor suppression. Cell 133, 403-414

44. Mayer, I. A., and Arteaga, C. L. (2016) The PI3K/AKT Pathway as a Target for Cancer Treatment. Annu Rev Med 67, 11-28

45. Manning, B. D., and Cantley, L. C. (2007) AKT/PKB signaling: navigating downstream. Cell 129, 1261-1274

46. Guertin, D. A., and Sabatini, D. M. (2007) Defining the role of mTOR in cancer. Cancer Cell 12, 9-22

47. Cantley, L. C., and Neel, B. G. (1999) New insights into tumor suppression: PTEN suppresses tumor formation by restraining the phosphoinositide 3kinase/AKT pathway. Proc Natl Acad Sci U S A 96, 4240-4245

48. Huang, C. H., Mandelker, D., Schmidt-Kittler, O., Samuels, Y., Velculescu, V. E., Kinzler, K. W., Vogelstein, B., Gabelli, S. B., and Amzel, L. M. (2007) The structure of a human p110alpha/p85alpha complex elucidates the effects of oncogenic PI3Kalpha mutations. Science 318, 1744-1748 
49. Hao, Y., Wang, C., Cao, B., Hirsch, B. M., Song, J., Markowitz, S. D., Ewing, R. M., Sedwick, D., Liu, L., Zheng, W., and Wang, Z. (2013) Gain of interaction with IRS1 by p110alpha-helical domain mutants is crucial for their oncogenic functions. Cancer Cell 23, 583-593

50. Burke, J. E., Perisic, O., Masson, G. R., Vadas, O., and Williams, R. L. (2012) Oncogenic mutations mimic and enhance dynamic events in the natural activation of phosphoinositide 3-kinase p110alpha (PIK3CA). Proc Natl Acad Sci U S A 109, 15259-15264

51. Philp, A. J., Campbell, I. G., Leet, C., Vincan, E., Rockman, S. P., Whitehead, R. H., Thomas, R. J., and Phillips, W. A. (2001) The phosphatidylinositol 3'-kinase p85alpha gene is an oncogene in human ovarian and colon tumors. Cancer Res 61, 7426-7429

52. Jaiswal, B. S., Janakiraman, V., Kljavin, N. M., Chaudhuri, S., Stern, H. M., Wang, W., Kan, Z., Dbouk, H. A., Peters, B. A., Waring, P., Dela Vega, T., Kenski, D. M., Bowman, K. K., Lorenzo, M., Li, H., Wu, J., Modrusan, Z., Stinson, J., Eby, M., Yue, P., Kaminker, J. S., de Sauvage, F. J., Backer, J. M., and Seshagiri, S. (2009) Somatic mutations in p85alpha promote tumorigenesis through class IA PI3K activation. Cancer Cell 16, 463-474

53. Kohn, A. D., Summers, S. A., Birnbaum, M. J., and Roth, R. A. (1996) Expression of a constitutively active Akt Ser/Thr kinase in 3T3-L1 adipocytes stimulates glucose uptake and glucose transporter 4 translocation. J Biol Chem 271, 31372-31378

54. Gottlob, K., Majewski, N., Kennedy, S., Kandel, E., Robey, R. B., and Hay, N. (2001) Inhibition of early apoptotic events by Akt/PKB is dependent on the first committed step of glycolysis and mitochondrial hexokinase. Genes Dev 15, 14061418

55. Deprez, J., Vertommen, D., Alessi, D. R., Hue, L., and Rider, M. H. (1997) Phosphorylation and activation of heart 6-phosphofructo-2-kinase by protein kinase $\mathrm{B}$ and other protein kinases of the insulin signaling cascades. J Biol Chem 272, 17269-17275

56. Duvel, K., Yecies, J. L., Menon, S., Raman, P., Lipovsky, A. I., Souza, A. L., Triantafellow, E., Ma, Q., Gorski, R., Cleaver, S., Vander Heiden, M. G., MacKeigan, J. P., Finan, P. M., Clish, C. B., Murphy, L. O., and Manning, B. D. (2010) Activation of a metabolic gene regulatory network downstream of mTOR complex 1. Mol Cell 39, 171-183

57. Sun, Q., Chen, X., Ma, J., Peng, H., Wang, F., Zha, X., Wang, Y., Jing, Y., Yang, H., Chen, R., Chang, L., Zhang, Y., Goto, J., Onda, H., Chen, T., Wang, M. R., Lu, Y., You, H., Kwiatkowski, D., and Zhang, H. (2011) Mammalian target of rapamycin up-regulation of pyruvate kinase isoenzyme type M2 is critical for aerobic glycolysis and tumor growth. Proc Natl Acad Sci U S A 108, 4129-4134

58. Christofk, H. R., Vander Heiden, M. G., Harris, M. H., Ramanathan, A., Gerszten, R. E., Wei, R., Fleming, M. D., Schreiber, S. L., and Cantley, L. C. (2008) The M2 splice isoform of pyruvate kinase is important for cancer metabolism and tumour growth. Nature 452, 230-233

59. Nutt, L. K. (2012) The Xenopus oocyte: a model for studying the metabolic regulation of cancer cell death. Semin Cell Dev Biol 23, 412-418 
60. Riganti, C., Gazzano, E., Polimeni, M., Aldieri, E., and Ghigo, D. (2012) The pentose phosphate pathway: an antioxidant defense and a crossroad in tumor cell fate. Free Radic Biol Med 53, 421-436

61. Jiang, P., Du, W., Wang, X., Mancuso, A., Gao, X., Wu, M., and Yang, X. (2011) p53 regulates biosynthesis through direct inactivation of glucose-6-phosphate dehydrogenase. Nat Cell Biol 13, 310-316

62. Ying, H., Kimmelman, A. C., Lyssiotis, C. A., Hua, S., Chu, G. C., FletcherSananikone, E., Locasale, J. W., Son, J., Zhang, H., Coloff, J. L., Yan, H., Wang, W., Chen, S., Viale, A., Zheng, H., Paik, J. H., Lim, C., Guimaraes, A. R., Martin, E. S., Chang, J., Hezel, A. F., Perry, S. R., Hu, J., Gan, B., Xiao, Y., Asara, J. M., Weissleder, R., Wang, Y. A., Chin, L., Cantley, L. C., and DePinho, R. A. (2012) Oncogenic Kras maintains pancreatic tumors through regulation of anabolic glucose metabolism. Cell 149, 656-670

63. Gao, L., Mejias, R., Echevarria, M., and Lopez-Barneo, J. (2004) Induction of the glucose-6-phosphate dehydrogenase gene expression by chronic hypoxia in PC12 cells. FEBS Lett 569, 256-260

64. Hong, X., Song, R., Song, H., Zheng, T., Wang, J., Liang, Y., Qi, S., Lu, Z., Song, X., Jiang, H., Liu, L., and Zhang, Z. (2014) PTEN antagonises Tcl1/hnRNPK-mediated G6PD pre-mRNA splicing which contributes to hepatocarcinogenesis. Gut 63, 1635-1647

65. Dworkin, M. B., and Dworkin-Rastl, E. (1989) Metabolic regulation during early frog development: glycogenic flux in Xenopus oocytes, eggs, and embryos. Dev Biol 132, 512-523

66. Nutt, L. K., Margolis, S. S., Jensen, M., Herman, C. E., Dunphy, W. G., Rathmell, J. C., and Kornbluth, S. (2005) Metabolic regulation of oocyte cell death through the CaMKII-mediated phosphorylation of caspase-2. Cell 123, 89-103

67. McCoy, F., Darbandi, R., Lee, H. C., Bharatham, K., Moldoveanu, T., Grace, C. R., Dodd, K., Lin, W., Chen, S. I., Tangallapally, R. P., Kurokawa, M., Lee, R. E., Shelat, A. A., Chen, T., Green, D. R., Harris, R. A., Lin, S. H., Fissore, R. A., Colbran, R. J., and Nutt, L. K. (2013) Metabolic activation of CaMKII by coenzyme A. Mol Cell 52, 325-339

68. Nutt, L. K., Buchakjian, M. R., Gan, E., Darbandi, R., Yoon, S. Y., Wu, J. Q., Miyamoto, Y. J., Gibbons, J. A., Andersen, J. L., Freel, C. D., Tang, W., He, C., Kurokawa, M., Wang, Y., Margolis, S. S., Fissore, R. A., and Kornbluth, S. (2009) Metabolic control of oocyte apoptosis mediated by 14-3-3zeta-regulated dephosphorylation of caspase-2. Dev Cell 16, 856-866

69. McCoy, F., Darbandi, R., Chen, S. I., Eckard, L., Dodd, K., Jones, K., Baucum, A. J., 2nd, Gibbons, J. A., Lin, S. H., Colbran, R. J., and Nutt, L. K. (2013) Metabolic regulation of CaMKII protein and caspases in Xenopus laevis egg extracts. J Biol Chem 288, 8838-8848

70. Smythe, C., and Newport, J. W. (1991) Systems for the study of nuclear assembly, DNA replication, and nuclear breakdown in Xenopus laevis egg extracts. Methods Cell Biol 35, 449-468

71. Fry, M. J. (2009) Phosphoinositide (PI) 3-kinase assays. Methods Mol Biol 462, 345-362 
72. Schneider, C. A., Rasband, W. S., and Eliceiri, K. W. (2012) NIH Image to ImageJ: 25 years of image analysis. Nat Methods 9, 671-675

73. Tidow, H., and Nissen, P. (2013) Structural diversity of calmodulin binding to its target sites. FEBS J 280, 5551-5565

74. Sorensen, A. B., Sondergaard, M. T., and Overgaard, M. T. (2013) Calmodulin in a heartbeat. FEBS J 280, 5511-5532

75. Linse, S., Helmersson, A., and Forsen, S. (1991) Calcium binding to calmodulin and its globular domains. J Biol Chem 266, 8050-8054

76. VanScyoc, W. S., Sorensen, B. R., Rusinova, E., Laws, W. R., Ross, J. B., and Shea, M. A. (2002) Calcium binding to calmodulin mutants monitored by domain-specific intrinsic phenylalanine and tyrosine fluorescence. Biophys $\mathrm{J} 83$, 2767-2780

77. Yamniuk, A. P., and Vogel, H. J. (2004) Calmodulin's flexibility allows for promiscuity in its interactions with target proteins and peptides. Mol Biotechnol 27, 33-57

78. Hoeflich, K. P., and Ikura, M. (2002) Calmodulin in action: diversity in target recognition and activation mechanisms. Cell 108, 739-742

79. Vogel, H. J. (1994) The Merck Frosst Award Lecture 1994. Calmodulin: a versatile calcium mediator protein. Biochem Cell Biol 72, 357-376

80. Chin, D., and Means, A. R. (2000) Calmodulin: a prototypical calcium sensor. Trends Cell Biol 10, 322-328

81. Yap, K. L., Kim, J., Truong, K., Sherman, M., Yuan, T., and Ikura, M. (2000) Calmodulin target database. J Struct Funct Genomics 1, 8-14

82. Weiss, W., Weiland, F., and Gorg, A. (2009) Protein detection and quantitation technologies for gel-based proteome analysis. Methods Mol Biol 564, 59-82

83. Joyal, J. L., Burks, D. J., Pons, S., Matter, W. F., Vlahos, C. J., White, M. F., and Sacks, D. B. (1997) Calmodulin activates phosphatidylinositol 3-kinase. J Biol Chem 272, 28183-28186

84. Fischer, R., Julsgart, J., and Berchtold, M. W. (1998) High affinity calmodulin target sequence in the signalling molecule PI 3-kinase. FEBS Lett 425, 175-177

85. Rordorf-Nikolic, T., Van Horn, D. J., Chen, D., White, M. F., and Backer, J. M. (1995) Regulation of phosphatidylinositol 3'-kinase by tyrosyl phosphoproteins. Full activation requires occupancy of both $\mathrm{SH} 2$ domains in the $85-\mathrm{kDa}$ regulatory subunit. J Biol Chem 270, 3662-3666

86. Fresno Vara, J. A., Casado, E., de Castro, J., Cejas, P., Belda-Iniesta, C., and Gonzalez-Baron, M. (2004) PI3K/Akt signalling pathway and cancer. Cancer Treat Rev 30, 193-204

87. Arcaro, A., and Wymann, M. P. (1993) Wortmannin is a potent phosphatidylinositol 3-kinase inhibitor: the role of phosphatidylinositol 3,4,5trisphosphate in neutrophil responses. Biochem J 296 ( Pt 2), 297-301

88. Vlahos, C. J., Matter, W. F., Hui, K. Y., and Brown, R. F. (1994) A specific inhibitor of phosphatidylinositol 3-kinase, 2-(4-morpholinyl)-8-phenyl-4H-1benzopyran-4-one (LY294002). J Biol Chem 269, 5241-5248

89. Connelly, T., Ahern, C., Sukhareva, M., and Coronado, R. (1994) Removal of $\mathrm{Mg} 2+$ inhibition of cardiac ryanodine receptor by palmitoyl coenzyme A. FEBS Lett 352, 285-290 
90. Zhao, L., and Vogt, P. K. (2010) Hot-spot mutations in p110alpha of phosphatidylinositol 3-kinase (pI3K): differential interactions with the regulatory subunit p85 and with RAS. Cell Cycle 9, 596-600

91. Ikenoue, T., Kanai, F., Hikiba, Y., Obata, T., Tanaka, Y., Imamura, J., Ohta, M., Jazag, A., Guleng, B., Tateishi, K., Asaoka, Y., Matsumura, M., Kawabe, T., and Omata, M. (2005) Functional analysis of PIK3CA gene mutations in human colorectal cancer. Cancer Res 65, 4562-4567

92. Kang, S., Bader, A. G., and Vogt, P. K. (2005) Phosphatidylinositol 3-kinase mutations identified in human cancer are oncogenic. Proc Natl Acad Sci U S A 102, 802-807

93. Zhao, J. J., Liu, Z., Wang, L., Shin, E., Loda, M. F., and Roberts, T. M. (2005) The oncogenic properties of mutant p110alpha and p110beta phosphatidylinositol 3-kinases in human mammary epithelial cells. Proc Natl Acad Sci U S A 102, 18443-18448

94. Bader, A. G., Kang, S., and Vogt, P. K. (2006) Cancer-specific mutations in PIK3CA are oncogenic in vivo. Proc Natl Acad Sci U S A 103, 1475-1479

95. Samuels, Y., Diaz, L. A., Jr., Schmidt-Kittler, O., Cummins, J. M., Delong, L., Cheong, I., Rago, C., Huso, D. L., Lengauer, C., Kinzler, K. W., Vogelstein, B., and Velculescu, V. E. (2005) Mutant PIK3CA promotes cell growth and invasion of human cancer cells. Cancer Cell 7, 561-573

96. Isakoff, S. J., Engelman, J. A., Irie, H. Y., Luo, J., Brachmann, S. M., Pearline, R. V., Cantley, L. C., and Brugge, J. S. (2005) Breast cancer-associated PIK3CA mutations are oncogenic in mammary epithelial cells. Cancer Res 65, 1099211000

97. Miled, N., Yan, Y., Hon, W. C., Perisic, O., Zvelebil, M., Inbar, Y., SchneidmanDuhovny, D., Wolfson, H. J., Backer, J. M., and Williams, R. L. (2007)

Mechanism of two classes of cancer mutations in the phosphoinositide 3-kinase catalytic subunit. Science 317, 239-242

98. Huang, C. H., Mandelker, D., Schmidt-Kittler, O., Samuels, Y., Velculescu, V. E., Kinzler, K. W., Vogelstein, B., Gabelli, S. B., and Amzel, L. M. (2007) The structure of a human p110alpha/p85alpha complex elucidates the effects of oncogenic PI3Kalpha mutations. Science 318, 1744-1748

99. Carson, J. D., Van Aller, G., Lehr, R., Sinnamon, R. H., Kirkpatrick, R. B., Auger, K. R., Dhanak, D., Copeland, R. A., Gontarek, R. R., Tummino, P. J., and Luo, L. (2008) Effects of oncogenic p110alpha subunit mutations on the lipid kinase activity of phosphoinositide 3-kinase. Biochem J 409, 519-524 


\section{VITA}

Rashid John Darbandi was born in 1985. He attended Duke University and graduated with a Bachelor of Science in Biology in 2007. In 2012, he joined the laboratory of Dr. Leta Nutt at St. Jude Children's Research Hospital as a research volunteer for 12 months. In the fall of 2013, Rashid enrolled in the Integrated Program in Biomedical Sciences at the University of Tennessee Health Science Center. He joined the lab of Dr. Leta Nutt in the Department of Pathology at St. Jude Children's Research Hospital where he has studied the metabolic regulation of cellular signaling. He is expected to graduate in August 2017 with a Doctor of Philosophy. 